\title{
How to Reach the New Green Deal Targets: Analysing the Necessary Burden Sharing within the EU Using a Multi-Model Approach
}

\author{
Felix Kattelmann*(D), Jonathan Siegle (D), Roland Cunha Montenegro, Vera Sehn, Markus Blesl and Ulrich Fahl 10
}

Citation: Kattelmann, F.; Siegle, J.; Cunha Montenegro, R.; Sehn, V.; Blesl, M.; Fahl, U. How to Reach the New Green Deal Targets: Analysing the Necessary Burden Sharing within the EU Using a Multi-Model Approach. Energies 2021, 14, 7971. https:// doi.org/10.3390/en14237971

Academic Editor: Chi-Ming Lai

Received: 31 October 2021

Accepted: 22 November 2021

Published: 29 November 2021

Publisher's Note: MDPI stays neutral with regard to jurisdictional claims in published maps and institutional affiliations.

Copyright: (c) 2021 by the authors. Licensee MDPI, Basel, Switzerland. This article is an open access article distributed under the terms and conditions of the Creative Commons Attribution (CC BY) license (https:/ / creativecommons.org/licenses/by/ $4.0 /)$.
Institute of Energy Economics and Rational Energy Use (IER), University of Stuttgart, 70565 Stuttgart, Germany; jonathan.siegle@ier.uni-stuttgart.de (J.S.); rolandcmontenegro@gmail.com (R.C.M.); vera.sehn@ier.uni-stuttgart.de (V.S.); Markus.Blesl@ier.uni-stuttgart.de (M.B.);

ulrich.fahl@ier.uni-stuttgart.de (U.F.)

* Correspondence: felix.kattelmann@ier.uni-stuttgart.de

\begin{abstract}
The Green Deal of the European Union defines extremely ambitious climate targets for 2030 ( $-55 \%$ emissions compared to 1990) and 2050 (-100\%), which go far beyond the current goals that the EU member states have agreed on thus far. The question of which sectors contribute how much has already been discussed, but is far from decided, while the question of which countries shoulder how much of the tightened reduction targets has hardly been discussed. We want to contribute significantly to answering these policy questions by analysing the necessary burden sharing within the EU from both an energy system and an overall macroeconomic perspective. For this purpose, we use the energy system model TIMES PanEU and the computational general equilibrium model NEWAGE. Our results show that excessively strong targets for the Emission Trading System (ETS) in 2030 are not system-optimal for achieving the 55\% overall target, reductions should be made in such a way that an emissions budget ratio of 39 (ETS sector) to 61 (Non-ETS sector) results. Economically weaker regions would have to reduce their $\mathrm{CO}_{2}$ emissions until 2030 by up to $33 \%$ on top of the currently decided targets in the Effort Sharing Regulation, which leads to higher energy system costs as well as losses in gross domestic product (GDP). Depending on the policy scenario applied, GDP losses in the range of $-0.79 \%$ and $-1.95 \%$ relative to baseline can be found for single EU regions. In the long-term, an equally strict mitigation regime for all countries in 2050 is not optimal from a system perspective; total system costs would be higher by $1.5 \%$. Instead, some countries should generate negative net emissions to compensate for non-mitigable residual emissions from other countries.
\end{abstract}

Keywords: Green Deal; burden sharing; effort sharing regulation; emissions trading system; energy system analysis; TIMES PanEU; NEWAGE

\section{Introduction}

The Green Deal [1] of the European Union (EU) specifies a very ambitious reduction in greenhouse gas (GHG) emissions by 2030 (-55\% compared to 1990), while complete climate neutrality in the EU is to be achieved by 2050.

The discrepancy between current targets for 2030 established in the European Union's Effort Sharing Regulation (ESR) and the new 2030 target imposed by the Green Deal raises the question of how and, more importantly, by whom this gap is to be closed.

On one hand, it must be discussed how the additional reductions are to be distributed between the European Union Emissions Trading System (ETS) and the Non-ETS sector (also referred to as the ESR sector in the following). While the EU Commission's proposals envisage a relatively balanced ratio of the burdens between the two systems, other studies see the necessity of significantly stronger reduction contributions in the ETS sector. 
On the other hand, the question emerges as to which countries will contribute these additional reductions. According to the effort-sharing that has been enacted thus far, the reductions in the Non-ETS sector are not distributed equally among the countries, but take into account "the different capacities of Member States to take action by differentiating targets according to gross domestic product (GDP) per capita across Member States" as well as the "cost-effectiveness for those Member States with an above average GDP per capita" [2].

This leads to the issue of how far this distribution between countries should be adapted, taking into account the new, significantly more ambitious targets under the Green Deal. The focus of this paper is on the tightening of targets for 2030, but the long-term mitigation burdens that will result from achieving climate neutrality in 2050 are also addressed.

As shown in Section 2, we could not find any modelling study concerning the Green Deal that addresses burden-sharing between EU regions, neither with energy system models, nor with general equilibrium models. For this reason, we want to obtain new scientific insights with our paper by quantifying the required burden sharing within the EU because of the Green Deal and analysing the resulting economic implications in the European regions with regard to energy system costs and GDP.

Many studies have considered stronger mitigation in the ETS sector to be favourable to achieving the 2030 targets. We aim to contribute to this with TIMES PanEU by shedding light on the optimal distribution of mitigation burden between ETS and Non-ETS sectors from a system perspective.

Furthermore, we use TIMES PanEU to examine the techno-economic requirements for the energy system emerging from the general, EU-wide climate target for 2030. The computable general equilibrium model NEWAGE provides an independent macroeconomic perspective on this target. In this way, we can reach a comprehensive overall view of the Green Deal goal.

With TIMES PanEU, the Green Deal can be studied in terms of its impact on the energy system with a high level of technological detail. Since all sectors are mapped, it is suitable for the investigation of a far-reaching goal such as climate neutrality for the EU. We distinguish ourselves from the existing literature by not only considering the EU as a single entity, but by also mapping and analysing the individual countries of the EU in detail. With this approach, we are able to identify opposing effects of the Green Deal on individual countries or regions in Europe. We want to go into regional depth from an energy system perspective in order to explore the reduction burden of the individual countries and regions more precisely within the EU.

With NEWAGE, we look at macroeconomic developments, which particularly concern burden sharing between countries. NEWAGE does not have the same level of detail and precision in its representation of the energy system, but it takes repercussions between developments in different economic sectors into account, and thereby provides an independent view on the overall economic effects on EU regions.

The three key findings of the paper can be summarized as follows:

- An excessively strong focus on mitigation in the ETS sector in 2030 is not cost-optimal. Reductions should be made in a way between the ESR and ETS sectors so that an emissions budget ratio of 61 to 39 results, similar to what the EU Commission also proposes. Nevertheless, the ETS sector always provides the major contribution to emissions reductions in all scenarios until 2030, with $-60 \%$ emissions in the optimal scenario compared to 2005.

- From an energy system perspective, economically weaker countries should reduce their emissions significantly more by 2030 than previously envisaged in the ESR targets to achieve the EU-wide targets at optimal cost. Their respective additional reductions range from $27 \%$ to $33 \%$, depending on the regions. However, the macroeconomic studies show the high economic burdens that result from distributing emission budgets according to a gross EU27 + UK optimum, which makes support via compensation 
measures absolutely necessary. Depending on the policy scenario applied, GDP losses in the range of $-0.79 \%$ and $-1.95 \%$ relative to baseline can be found for single EU regions.

- To achieve climate neutrality in 2050 for the entire EU, an equally strict mitigation regime for all countries is not optimal from a system perspective, as total annualized system costs would be higher by $1.5 \%$ in this case. In particular, countries with large shares of agricultural emissions in their total emissions should not be given excessively strong targets. In contrast, countries with high biomass potentials should generate negative emissions to compensate for these residual emissions.

The rest of this work is structured as follows. In Section 2, we conduct an extensive literature review. Section 3 contains a brief description about the two models used and the general scenario framework. We then conduct our analyses of burden sharing in 2030 in Section 4, while we turn to the long-term analyses for the year 2050 in Section 5. Finally, we provide a short discussion of our results including an outlook for further research in Section 6 and the conclusions in Section 7.

\section{Literature Review}

In the literature before 2019, the energy scenario definitions mainly focussed on greenhouse gas reduction goals for Europe between 80 and $85 \%[3,4]$ or on analysing the renewable energies integration in the energy system [5-7]. There is a wide variety of modelling tools for energy scenario assessments [8], but we focussed on the ones calculating deep decarbonisation scenarios. The existing literature can be further divided into studies analysing the near future $[9,10]$ or the long-term effects. Energy system research, which considers the actual European targets for 2050 or the global target to limit climate change to $1.5^{\circ} \mathrm{C}$, shows a widely varying demand for bioenergy plus carbon capture and storage (BECCS) to reach deep decarbonisation, reflecting the uncertainty of the remaining carbon dioxide $\left(\mathrm{CO}_{2}\right)$ budgets.

Pietzcker et al. [11] analysed the tightening of the European targets for 2030 and 2050 using the electricity market model LIMES EU. Their analysis showed a faster transformation of the ETS sector with an earlier phase-out of coal and accelerated expansion of renewable energy sources. The more ambitious targets led to the deployment of BECCS above a carbon price level of $100 € / \mathrm{t} \mathrm{CO}_{2}$ Furthermore, they found a rather limited effect of BECCS availability on carbon emissions as well as on carbon and electricity prices.

Luderer et al. [12] used seven integrated assessment models (IAM) to analyse residual $\mathrm{CO}_{2}$ emissions from fossil fuels under the $1.5^{\circ} \mathrm{C}$ goal. They assumed a global budget of $200 \mathrm{Gt} \mathrm{CO} 2$ between 2016 and 2100 to keep global warming below $1.5^{\circ} \mathrm{C}$. According to their research, a significant amount of ca. $800 \mathrm{Gt}$ of residual $\mathrm{CO}_{2}$ emissions will need to be stored, even under strict mitigation policies. Delayed policy action further increases this amount substantially.

In a study with the energy system model PROMETHEUS, Fragkos evaluated higher $\mathrm{CO}_{2}$ budgets to limit the global warming to $1.5^{\circ} \mathrm{C}$ [13] to account for new budget estimates from the IPCC Special Report on the impacts of global warming of $1.5{ }^{\circ} \mathrm{C}$ [14]. The author suggests that, for a $\mathrm{CO}_{2}$ budget of $860 \mathrm{Gt}$ and depending on the respective scenario assumptions, the quantity of $\mathrm{CO}_{2}$ captured by BECCS to reach net zero emissions varies between 0 and $205 \mathrm{Gt}$.

In a study with the model GENeSYS-MOD, the implications of the $2{ }^{\circ} \mathrm{C}$ and a $1.5^{\circ} \mathrm{C}$ climate scenario on the European energy system were analysed and compared to a businessas-usual scenario [15]. Hainsch et al. concluded that the transformation to renewable energies is mostly market driven, while further decarbonisation requires policy action. BECCS technology is only applied in the $1.5^{\circ} \mathrm{C}$ scenario, but the need for carbon capture technologies and their cost-effectiveness might be underestimated because the model does not include some sectors of the economy (e.g., agriculture and a few branches of the industry). 
A similar study was performed with the PyPSA model, which represents the energy, heat, and transport sector [16]. An early and steady decarbonisation pathway of the European energy system was compared with a late and rapid decarbonisation, while the carbon budget for minimizing climate change to $1.75^{\circ} \mathrm{C}$ was applied to both scenarios. They identified the early decarbonisation scenario as the one with the lowest system costs and the energy mix being mainly based on photovoltaic and wind technologies while deployment of BECCS is not required.

In most of the studies, deep decarbonisation requires not only the integration of renewable energies, but also of several hydrogen and negative emission technologies. Sgobbi et al. investigated several hydrogen technologies within the JRC-EU-TIMES model and emphasised its importance to decarbonise the transport and industry sector, gaining even more relevance if negative emission technologies are to be lately deployed [17].

Klein et al. analysed the deployment of biofuelled integrated-gasifiation-combinedcycle (Bio-IGCC) with Carbon Capture \& Storage (CCS) technology in the integrated assessment model REMIND and reviewed that the deployment was more sensitive to price changes of the biomass than to different techno-economic parameters of the Bio-IGCC process itself [18]. Davis et al. investigated the limits of BECCS technologies and argued that their potential was not only limited by the geological storage capacity of $\mathrm{CO}_{2}$, but also by the required land area, nutrient demand, and water use. Regarding the economic aspects, BECCS seems to be a cost-effective mitigation option for the energy system because the deployment of the BECCS technology can be observed even in less ambitious climate scenarios, but it appears as a risky mitigation option to the authors in comparison to an immediate and strong GHG reduction [19].

In its Impact Assessment on the revised 2030 climate target, the European Commission provides an in-depth analysis of consequences in various aspects [20]. The European Commission employs three modelling tools to evaluate macro-economic effects of the new target under different assumptions. Results from all three modelling tools presented only moderate GDP effects at the EU level. GDP deviation from baseline was below $1 \%$ for all models and assumptions, for some slightly negative and for others slightly positive. Regarding sectoral output developments, the results of the JRC-GEM-E3 CGE model showed severe losses in the fossil fuel sectors. Developments in energy-intensive sectors with strong international competition depend heavily on the level of global climate action. Deviations from baseline are usually negative for fragmented action and positive for global action. Observed impacts on employment are generally very limited. However, employment impacts in the fossil fuels sectors are strong, especially in the coal sector.

The European Commission also evaluates several options of future ETS and ESR design. Continuation of the current ETS and ESR scope would require significant tightening of the reduction targets in one or both of the systems. Adjusting the ETS to the revised 2030 target could include an adjustment of the linear reduction factor or a one-off cap-reduction. The Impact Assessment also mentions the option of not strengthening the current ESR targets at all, at the expense of even further tightened ETS targets.

Furthermore, the Impact Assessment discusses in detail a scope extension of the ETS. This approach is subject to several publications (e.g., by Meyer-Ohlendorf and Barth [21]). According to the analysis of the European Commission, extension of the ETS sectoral coverage to buildings and road transport induces lower emission reductions in these sectors. In particular, the transport sectors' response to ETS carbon prices is considered weak due to the already high level of energy and national carbon taxation within Member States.

Current ESR targets were established with respect to GDP per capita within Member States to ensure fairness between higher and lower income countries [2]. The EU Commission also provided an Inception Impact Assessment specifically on the review of the ESR in light of the revised 2030 target and the goal of climate neutrality by 2050 [22]. According to this document, the review of the ESR has four objectives on a more specific level: (...) "incentives for the necessary additional action in the effort sharing sectors should 
be provided, cost-effective solutions should be promoted, Member States' efforts should be shared in a fair and consistent manner, and coherence with related legislation should be maintained". Recently, the European Commission's proposal for the buildings and transport sector seems to shape up as an inclusion of these sectors in the ETS, possibly in a separated system [23].

Babonneau et al. evaluated the 2016 effort sharing suggestions of the EU commission related to the $80 \%$ GHG mitigation target in 2050 related to 1990 [24]. According to their results, application of burden sharing to all sectors is more beneficial in terms of welfare for low income member states, while high income member states benefit from an application of the ETS to all sectors.

We could not find any modelling study concerning the Green Deal that addresses burden-sharing between EU regions, neither with energy system models, nor with general equilibrium models. This paper aims to deepen the understanding of the implications of achieving the 2030 target through a combined exploration of the Green Deal from both an energy system and an economics perspective.

Multiple studies consider stronger mitigation in the ETS sector to be favourable for achieving the 2030 targets. We aim to contribute to this with TIMES PanEU by shedding light on the optimal distribution of mitigation burden between ETS and Non-ETS sectors from a system perspective.

By comparing the literature, one can observe that the need for negative emissions relies on how many sectors of the energy system are covered within the model. While assessments with IAMs opt for the deployment of BECCS technologies, the studies with energy system models covering not all sectors review these technologies as unnecessary. As a full sectoral coverage is crucial for the energy scenario analysis, this work further investigates the significance of negative emissions for the implementation of the Green Deal.

\section{Methodology}

For this study, we employed an energy system model, TIMES-PanEU, and the computable general equilibrium (CGE) model NEWAGE. Captured emissions, determined by TIMES, were used as input for NEWAGE. This section further explains the two modelling tools.

\subsection{TIMES PanEU}

Energy system models are a widely used tool for analysing the techno-economic implications of policy imperatives such as emission targets for countries or regions. They have been successfully employed to analyse emission targets in a large number of publications (e.g., $[13,15,18,25])$ and the European Commission's Joint Research Centre (JRC) uses a different model [26], which was derived from the same model framework utilised in this study.

TIMES PanEU was applied in this study as an energy system model. This section provides a very brief description of the underlying mechanics, basic correlations within the energy system, and information about the assumptions on the costs and potentials that we established for this study. For a more detailed description of the model, please refer to $[25,27,28]$.

The fundamental framework of the model is the reference energy system (RES). As can be seen in Figure 1, the RES maps all energy carriers, technologies, materials, emission flows, and service demands, which are necessary to thoroughly depict the energy system. It covers the complete energy system, beginning with the supply of resources and energy carriers and ending with the fulfilment of the defined demands. Primary energy can be converted into secondary energy before being used as final energy, multiple times, taking into account the respective costs and efficiencies of the conversion steps. The consumption of fossil energy sources causes emissions, whereby the greenhouse gases $\mathrm{CO}_{2}$, methane $\left(\mathrm{CH}_{4}\right)$, and nitrous oxide $\left(\mathrm{N}_{2} \mathrm{O}\right)$ were considered in the scope of this study. 


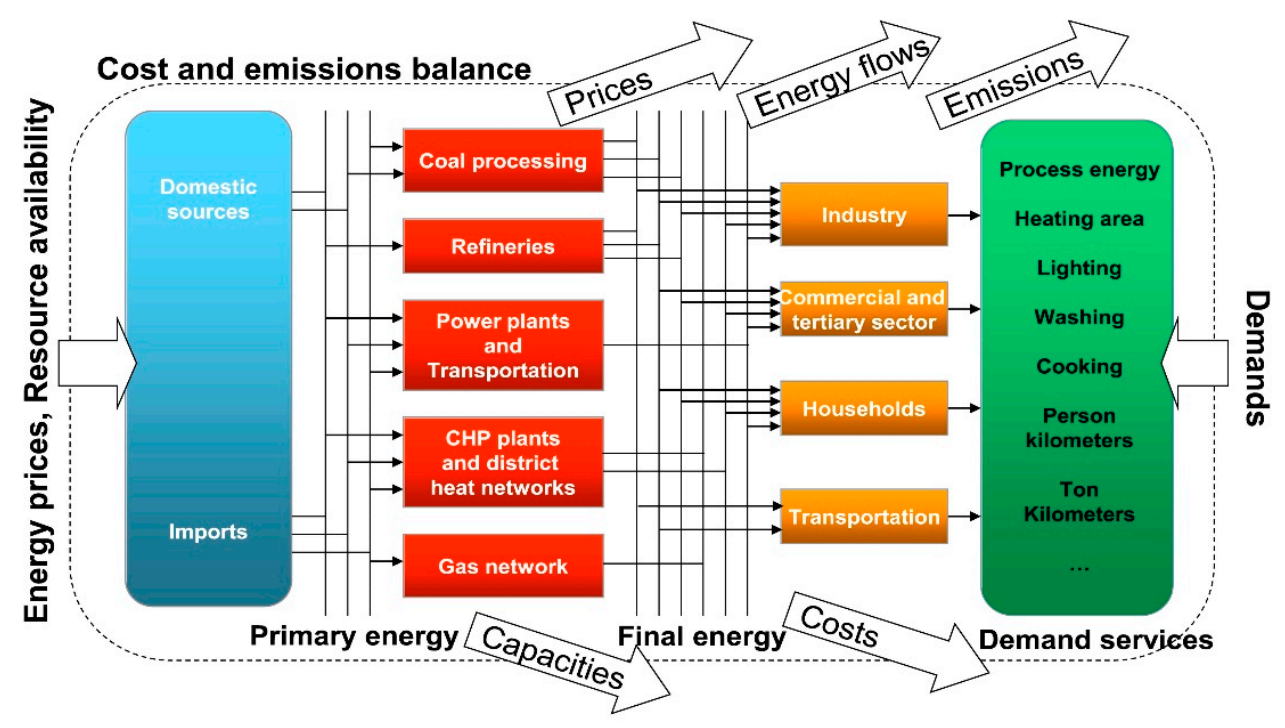

Figure 1. TIMES PanEU reference energy system [28].

Technologies are mapped with investment costs, fixed and variable costs, lifetimes and efficiencies, energy carriers can be mined within a region, or imported at specified costs. Ultimately, all costs are included in the system cost function, which is to be minimised.

TIMES PanEU is a linear optimiser that aims to minimise the total discounted system cost in a given timeframe to meet exogenously given service demands [29]. It has perfect foresight over the whole modelled time horizon.

Our model covers all of the EU plus the United Kingdom (UK), Norway (NO), and Switzerland $(\mathrm{CH})$, with each country represented as an individual region with its unique energy system. Energy service demands must be met for every region, and interactions between the regions are mapped via trade in electricity, bioenergy as well as emissions.

The model horizon spans from 2010 to 2050, split into periods with a length of five years each. Periods are represented by a single year, with each year being divided into 12 time slices: one day for every season divided into a slice for the day, one for the night, and one peak hour, which covers the time of the day where maximal load occurs.

Additional to the described model structure in $[25,27,30]$, the TIMES PanEU model was further developed to consider the latest technology updates and policy-relevant developments.

Domestic hydrogen production was implemented. In addition to the hydrolysis, biomass and gas gasification options were integrated into the model to produce hydrogen. The techno-economic characteristics of the production technologies were taken from [26]. Hydrogen-fuelled technologies are also defined in each sector. Ammonia production is implemented into the model based on the Haber-Bosch process in the hydrogen and nitrogen [31]. Synfuels are employed to provide additional decarbonisation options, especially in the transport and industry sectors. For these energy carriers, import processes are defined for synthetic gas, synthetic kerosene, synthetic diesel, synthetic fuel oil, and synthetic gasoline. They are implemented as zero emission energy carriers.

Coal phase out commitments of the different Member States were integrated, based on [32]. By considering these discussions, coal and lignite CCS technologies were not defined as investment options for the respective countries.

The technological option to generate negative emissions was given to the model via the combination of electricity generation from biomass with downstream CCS, further referred to as BECCS. Biomass potential for every country was taken from [33]. Across the analysis, high biomass potential curves were integrated to the existing model structure. Renewable energy potentials were based on ENSRPESO [34] and livestock demand was reduced by 50\% until 2050, following the AT-Kearney Study [35]. However, this leaves residual emissions (especially $\mathrm{CH}_{4}$ ) that can be reduced by (costly and complex) technical 
measures, but not completely. A base amount of about $25 \%$ of agricultural emissions cannot be reduced.

The GHG abatement options for the process emissions in the agriculture sector were derived from [36]. Import prices for fossil fuels were taken from the "Sustainable Development Scenario" in [37].

\subsection{NEWAGE}

For the analysis of the macroeconomic effects of different scenarios, we employed the CGE model NEWAGE (Model website as of 25.11.2021: https: / / www.ier.uni-stuttgart.de/ en/research/models/NEWAGE/, accessed on 21 Novemeber 2021). CGE models are a well-established class of macroeconomic models already used previously in the evaluation of current EU effort sharing [24]. One of the models used in the European Commission's Impact Assessment is also a CGE model (JRC-GEM-E3) [38].

NEWAGE's representation of the energy sector is not as precise as TIMES Pan-EU's. However, NEWAGE takes income and demand effects into account. Economy is modelled in a "closed loop" with its interconnections between consumers and industry sectors. Moreover, NEWAGE covers not only the EU, but the whole world. Therefore, it facilitates the analysis of repercussions of energy-related policy decisions in the worldwide economy. In the following, a brief overview on the basic features of the model is given.

NEWAGE is applied in a recursive-dynamic manner and does not have foresight. The base year is 2011, followed by 2015, and further five-year time steps until 2050. Production of goods and services is split into 23 sectors. Underlying trade data are taken from the GTAP 9 [39] and EXIOBASE 3 [40] databases. Production is modelled with Constant Elasticity of Substitution (CES) functions. A special feature of NEWAGE is the representation of the electricity sector with 18 different electricity generation technologies. In its current version, NEWAGE includes not the full spectrum of greenhouse gas emissions, but only energetic $\mathrm{CO}_{2}$ emissions. For more details on the structure of production and electricity generation in NEWAGE, see Appendix B.

In NEWAGE, the world is represented by 18 regions. Some large countries make up a region by themselves, but most countries are aggregated into regions. For example, the Scandinavian and Baltic countries are combined with Ireland in the Northern EU region. Austria, Czech Republic, Hungary, Slovakia, Slovenia, Croatia, Romania, Bulgaria, Greece, Cyprus, and Malta make up the south-eastern EU region (see Figure 2 below).

\begin{tabular}{|l|l|l|}
\hline Region & $\begin{array}{l}\text { Short } \\
\text { Form }\end{array}$ & Colour \\
\hline $\begin{array}{l}\text { United } \\
\text { Kingdom }\end{array}$ & UKI & \\
\hline Germany & DEU & \\
\hline France & FRA & \\
\hline Italy & ITA & \\
\hline Poland & POL & \\
\hline $\begin{array}{l}\text { Spain }+ \\
\text { Portugal }\end{array}$ & ESP & \\
\hline Benelux & BNL & \\
\hline $\begin{array}{l}\text { Northern } \\
\text { EU }\end{array}$ & EUN & \\
\hline $\begin{array}{l}\text { South- } \\
\text { Eastern EU }\end{array}$ & EUS & \\
\hline
\end{tabular}

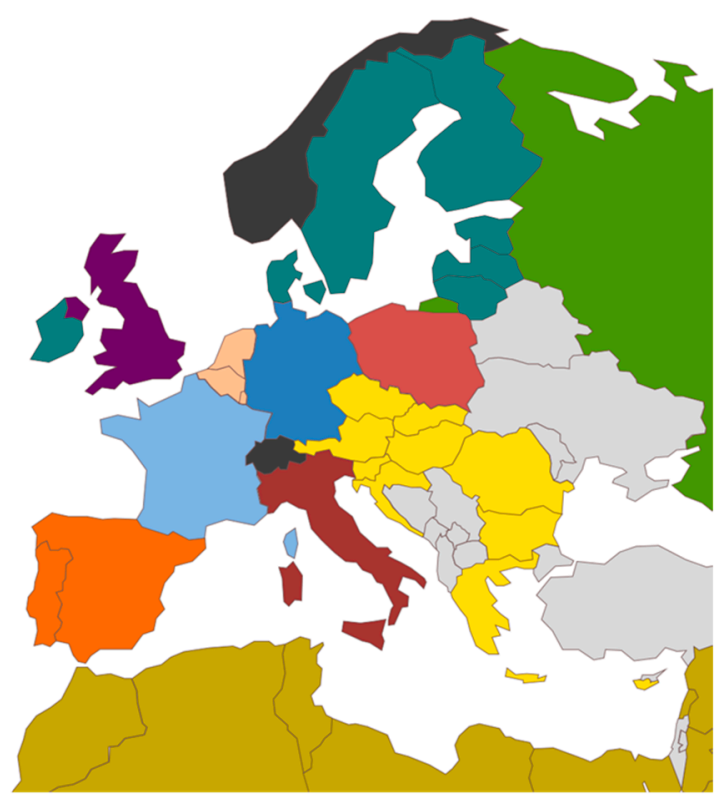

Figure 2. NEWAGE regions in EU 27 + the United Kingdom. 
NEWAGE calculations consider trade flows among world regions. In all scenarios calculated for this article, prices of fossil fuels in the regions with the largest fossil fuel resources were fixed at values given by the sustainable development scenario of IEA [37].

\subsection{Scenario Framework}

For this study, we examined three main scenarios. All three scenarios were based on the goals of the EU Commission's Green Deal (i.e., 100\% greenhouse gas neutrality for the entire EU is achieved by 2050).

- Optimal (OPT):

Reaching the primary climate targets without additional restrictions regarding the distribution between ETS and ESR or between the countries exceeding the already agreed distributions.

- $\quad$ ETS first:

Reaching the climate targets, but with a major contribution from the ETS sector that has to be completely GHG-neutral by 2050 . However, there are no restrictions regarding the burden sharing between the countries in the ETS sector. Reductions already agreed upon in the ESR sector will be extrapolated until 2050.

- $\quad$ ESR more:

Meeting the climate targets, but with a major contribution from the ESR sectors, these must reduce GHG emissions by $95 \%$ until 2050 (compared to 2005). However, each country must reduce its emissions by at least $80 \%$. The ETS sector must achieve slightly higher reductions than the optimal scenario.

The precise reduction targets we have specified for each scenario can be found in Table 1. Please note that the targets refer to the EU plus the UK. We included the UK alongside the EU in the targets of the scenarios to ensure comparability with the current Effort Sharing Regulation, which still includes the UK. In NEWAGE, $\mathrm{CO}_{2}$ reduction goals for regions outside $\mathrm{EU}+$ the United Kingdom were derived from the sustainable development scenario of IEA [37].

Table 1. GHG emission targets in the three scenarios. Emissions from waste and LULUCF are not included.

\begin{tabular}{ccccc}
\hline Year & Scenario & $\begin{array}{c}\text { ETS Sector } \\
{[41]}\end{array}$ & $\begin{array}{c}\text { ESR Sector } \\
\text { 1 }\end{array}$ & $\begin{array}{c}\text { Overall GHG } \\
{[42,43]}\end{array}$ \\
\hline 2005 & Statistics & $2360 \mathrm{Mt}$ & $2677 \mathrm{Mt}$ & $5037 \mathrm{Mt}$ \\
\hline \multirow{2}{*}{2030} & OPT & $-43 \%$ & $-30 \%$ & \\
& ETS first & $-77 \%$ & $-30 \%$ & $-55 \%$ \\
& ESR more & $-58 \%$ & $-47 \%$ & \\
\hline \multirow{2}{*}{2050} & OPT & $-43 \%$ & $-30 \%$ & $-100 \%$ \\
& ETS first & $-100 \%$ & $-30 \%$ & \\
\hline
\end{tabular}

${ }^{1}$ The country-specific ESR targets can be found in Table A1 in Appendix A.

\section{Optimal Burden Sharing in 2030 to Reach the Goal of $55 \%$ Reduction}

The objective of the following first part of the results analysis is to provide answers to these two questions:

- What mitigation in the ETS and ESR sectors is optimal from a system perspective in 2030?

- Which countries or regions should shoulder which burden in 2030?

We examined both issues always under the condition that the $55 \%$ reduction target in 2030 for the EU as a whole is achieved.

We begin the analyses of burden sharing with the allocation of the mitigation efforts between the sectors covered by the ETS and the sectors not covered by the ETS, the 
ESR sectors. We then move on to the burden sharing between the countries of the EU, first from an energy system point of view before supplementing the assessment with a macroeconomic perspective.

\subsection{Burden Sharing between ETS and ESR Sectors}

We conducted the analysis of the optimal allocation of abatements between ETS and ESR by examining the distribution of the 2030 emissions budget between the ETS and ESR sectors. The corresponding budgets for the three scenarios can be found in Figure 3.
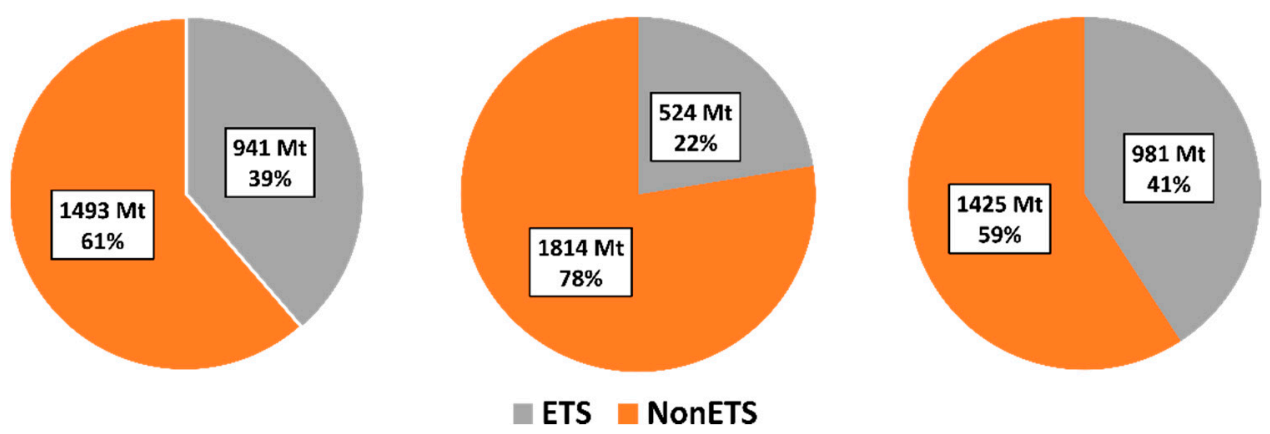

Figure 3. Emission budget for the ETS and Non-ETS in 2030 (Optimal, ETS first, ESR more).

Our model calculations with TIMES PanEU indicated a share for the ESR sector of the overall GHG emissions of about $61 \%$ in the optimal scenario for 2030 . Currently, this share is at $57 \%$, and the proposals of the EU Commission would also yield to a similar share of $61 \%$ in the medium-term. Hence, this is already the first interesting finding, as other studies [44] have derived significantly higher shares of about $80 \%$ for the budget of the ESR sector. Unfortunately, it is not clear from the study cited how the applied model is structured, so we cannot conclusively determine whether these differences are due to different implementations of ETS or ESR in the model.

The comparison of the three scenarios showed particularly large deviations in ETS first compared to the other two. In Figure 4, it is evident that the ETS sector mitigated significantly more in relation to 2005, and thus also departed substantially from the ratios in the Optimal and ESR more. However, all three scenarios shared in common that the ETS sector always contributed the greater part of the reductions, ranging from $-60 \%$ (Optimal) to $-78 \%$ (ETS first). Even in ESR more, with $-58 \%$, ETS sector reductions were greater than the $-55 \%$ specified in the scenario framework.

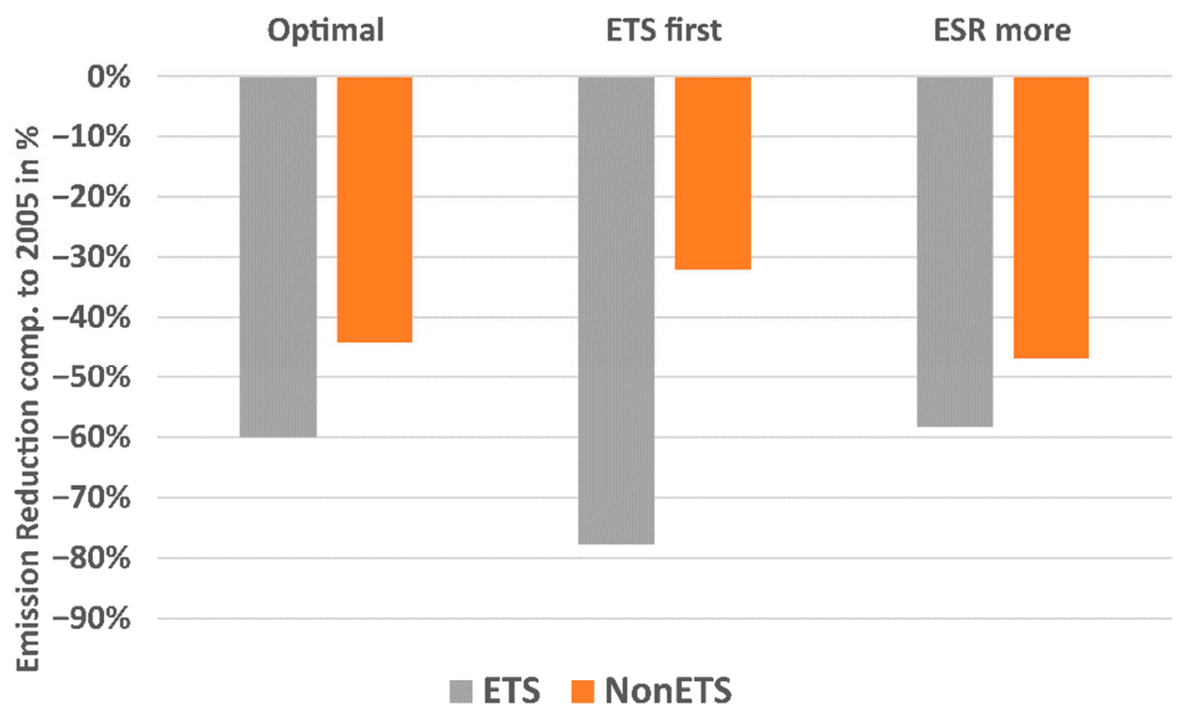

Figure 4. Greenhous gas emissions reduction in 2030. 
Nevertheless, with a reduction of $44 \%$, the ESR sector made a substantial contribution to the overall emission mitigation in our cost-optimal case. We conclude that a strong focus on the ETS sectors, as the ETS first scenario stipulates, is disadvantageous from a system perspective, which can also be deduced from the annuated system costs in 2030 where ETS first had $2.5 \%$ higher costs than the reference scenario compared to $1.3 \%$ for the Optimal scenario or $1.5 \%$ in ESR more.

We have identified two main reasons for this effect, which we will elaborate in the following:

1. In the optimal case, the building sector can cheaply reduce emissions to a certain amount through district heating; with tough ETS targets, this is limited in the mediumterm.

2. By burdening the power sector with the ETS targets, we obtain a higher electricity price, which ultimately leads to a decreased use of electricity-based technologies in the ESR sectors, particularly in the transport sector.

The expansion of district heating is a central component of the transformation of the energy system. The share of district heating in the final energy consumption of buildings rose between 2020 and 2030 from approximately $7 \%$ to roughly $12 \%$ in the Optimal scenario. For the building sector, this technology option represents a good option for reducing emissions in the medium- and long-term, especially as it is largely provided by efficient gas combined heat and power (CHP) plants in the medium-term. In the long-term, the district heating supply is then defossilised by shifting production to large-scale heat pumps, biomass-fired CHP plants, or geothermal energy.

Given a strong focus on the ETS sector, a large part of the gas-fired power plants cannot be operated in 2030 in order to achieve the reduction targets, as the ETS first scenario demonstrates. As can be seen in Figure 5a, this led to a considerably low share of heat in final energy consumption in the building sector, which dropped from around $12 \%$ (Optimal) to around 8\% (ETS first).

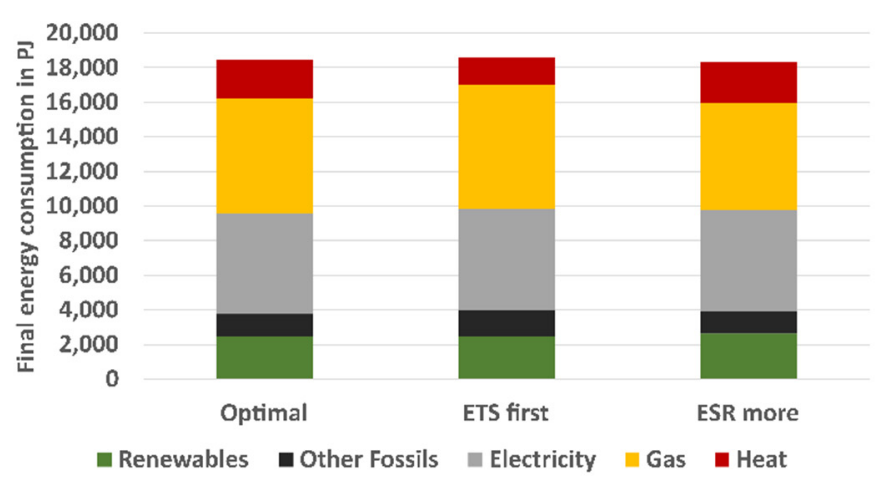

(a)

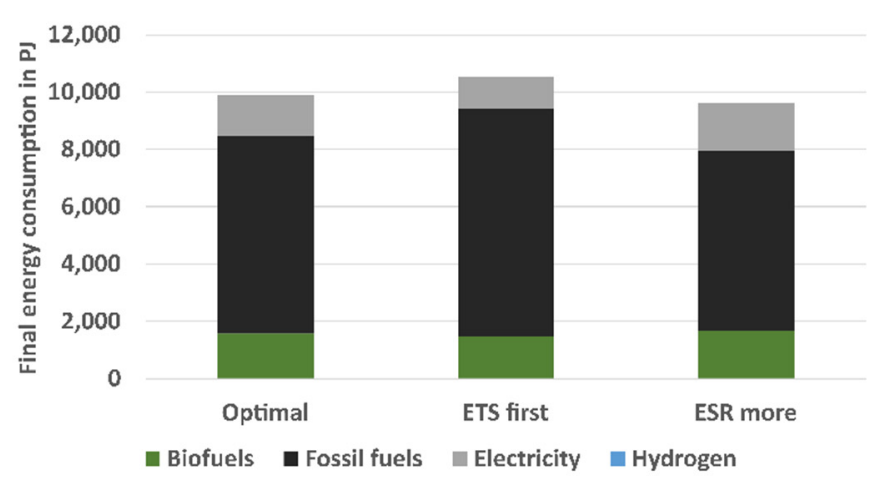

(b)

Figure 5. Final energy consumption in 2030 for (a) residential and commercial buildings and (b) the transport sector.

It emerges that in the case of ETS first, district heating was predominantly replaced by the direct combustion of gas. As a result, emissions in the ESR sector increased, while in the ETS sectors, emissions decreased by approx. $140 \mathrm{Mt} \mathrm{CO}_{2}$. This "shifting" of emissions ultimately accomplished the ETS goals, but makes little sense from an energy system perspective.

However, the building sector saw only a negligible decline in electricity consumption, which can be explained by the concurrent decrease in district heating. On one hand, the requirements imposed by ETS first increased the marginal costs for the supply of electricity, which in fact made electricity less attractive for the building sector. On the other hand, this effect could be found to a much greater extent in district heating. We therefore observed two effects running in opposite directions: District heating becomes less attractive for the 
building sector, but this does not trigger a stronger electrification due to the simultaneously rising electricity prices; the gap is filled by fossil energy sources.

As a second in-depth investigation, the impact of the ETS first on the transport sector will be elaborated by looking again at the final energy consumption in Figure $5 \mathrm{~b}$. We can see that in the case of the optimum in 2030, a significant share of the transport sector was already electrified (approx. 15\% of final energy). In TIMES PanEU, we assumed cost parity between electric and combustion engines until 2025. In the Optimal scenario, this led to an early electrification of the transport sector, resulting in 33 million fully electrically powered cars in the EU in 2030.

In ETS first, the share of electricity in the final energy consumption dropped to only $11 \%$ of the final energy consumption and the $4 \%$ difference to the Optimal scenario was completely replaced by fossil fuels. The higher costs of electricity generation due to the high reduction pressure in ETS first led to a decreasing economic appeal of electrical alternatives in transport. Here, just as in the building sector, a non-cost-optimal shift of emissions to the ESR sector takes place.

Overall, ETS first led to a lower electricity consumption of about 100 TWh compared to Optimal and also ESR more, which corresponded to a relative deviation of about 3\%. However, this difference occurred almost exclusively in the transport sector; other sectors were affected to a much lesser extent, as is described above for the building sector.

The conclusions of this chapter can thus be summarised as follows:

- Although a cost-optimal reduction to achieve the EU targets in 2030 leads to a relatively stronger reduction in the ETS sector, the ESR sector should also make its significant contribution, leading to a ratio of emissions of $39 \%$ to $61 \%$ (ETS/ESR).

- A too heavy focus on reductions in the ETS sector in 2030 leads to two negative effects: first, district heating, which optimally contributes to decarbonisation, is deployed less in the building sector (there was $8 \%$ of final energy consumption in ETS first compared to $12 \%$ in the Optimal scenario). Second, tightened targets for the power sector lead to higher electricity prices, meaning that electric options are less deployed in the transport sector, which results in higher emissions in that sector.

\subsection{Burden Sharing between the European Regions in 2030 from an Energy System Perspective}

This section analyses the burden sharing between the countries in 2030, which has become necessary through the tightened targets of the Green Deal.

As a first step, a comparison of the needed emission reductions in the EU Member States in the Optimal scenario with the targets for these countries that have been agreed in the ESR thus far was carried out for Non-ETS sectors. On one hand, the aim was to review the targets with regard to their suitability to achieve the $55 \%$ target for Europe in 2030. On the other hand, it is to be examined which countries should reduce their Non-ETS sector by how much from a system perspective. The comparison, shown in Figure 6, of the current targets with the Optimal shows that all countries reduced more than they are currently required to do by the Effort Sharing Regulation. The majority of countries even needed to reduce significantly more, so the ESR targets adopted thus far are nowhere near sufficient to achieve the $55 \%$ target in 2030 .

It is striking that Poland, Romania, and Bulgaria contributed a significantly higher reduction in the Optimal scenario. From a system perspective, countries that are "spared" in the ESR should actually reduce significantly more in the ESR sector. From a system perspective, economically weaker countries should contribute more to mitigation at an early stage than previously envisaged. 


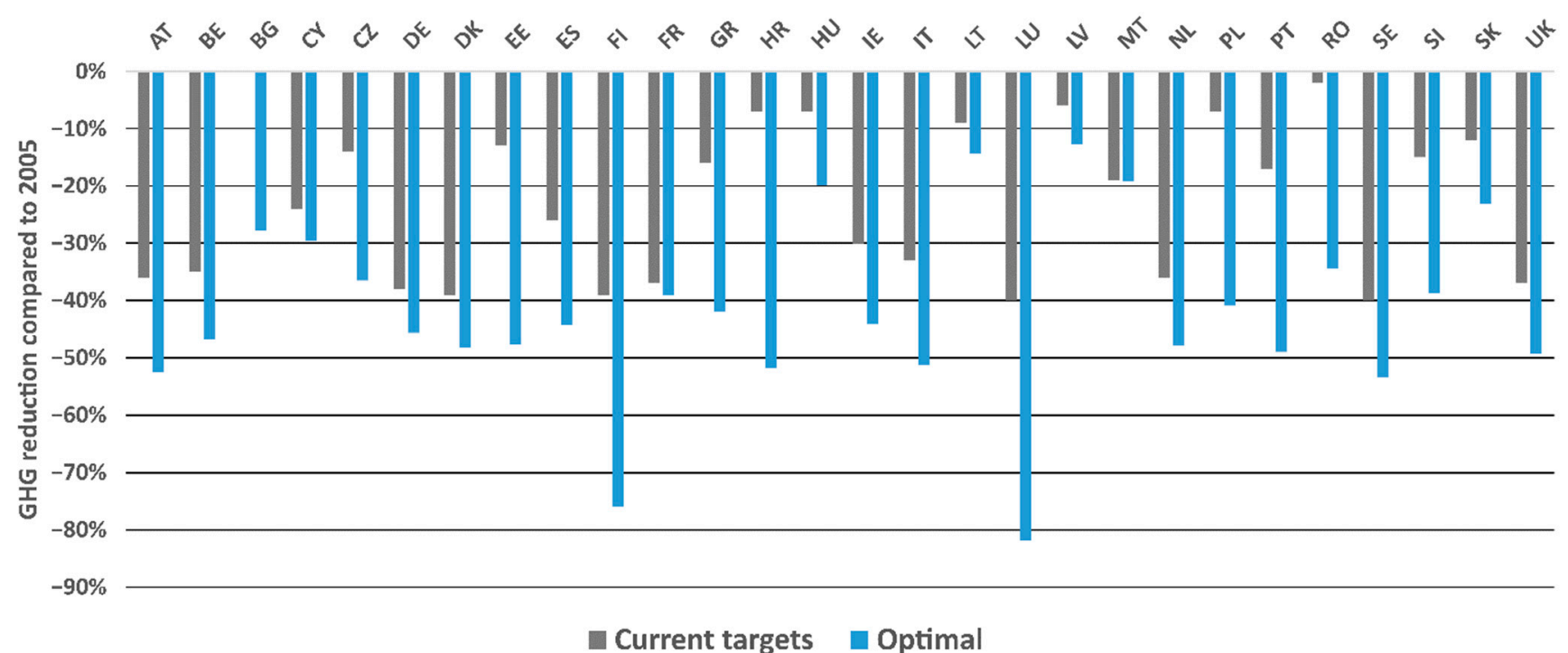

Figure 6. Country specific greenhouse gas reduction in the ESR sector against 2005 in the Optimal scenario in 2030 compared to the current targets, agreed in the Effort Sharing Regulation.

To examine the burden sharing between the countries and regions of Europe more deeply, we continued by determining the total $\mathrm{CO}_{2}$ reductions that the countries will have to provide in 2030 compared to a reference case to achieve the climate targets in this year. In this context, we only evaluated the $\mathrm{CO}_{2}$ emissions to facilitate comparisons with the NEWAGE results. However, the two remaining greenhouse gases were always part of the reduction requirement, regardless of this particular evaluation. To achieve better comparability between the models, we implemented a reference scenario to which we could compare the other scenarios. The scenario was defined as a business-as-usual scenario in which no reductions beyond the already adopted ETS and ESR targets are defined. NEWAGE does not assume any $\mathrm{CO}_{2}$ reduction targets outside the EU + United Kingdom in this scenario. The results of this analysis are shown in Figure 7. The countries of the EU were aggregated here according to the NEWAGE standard (see Section 3.2. NEWAGE) in order to be able to subsequently better compare the effects with NEWAGE.

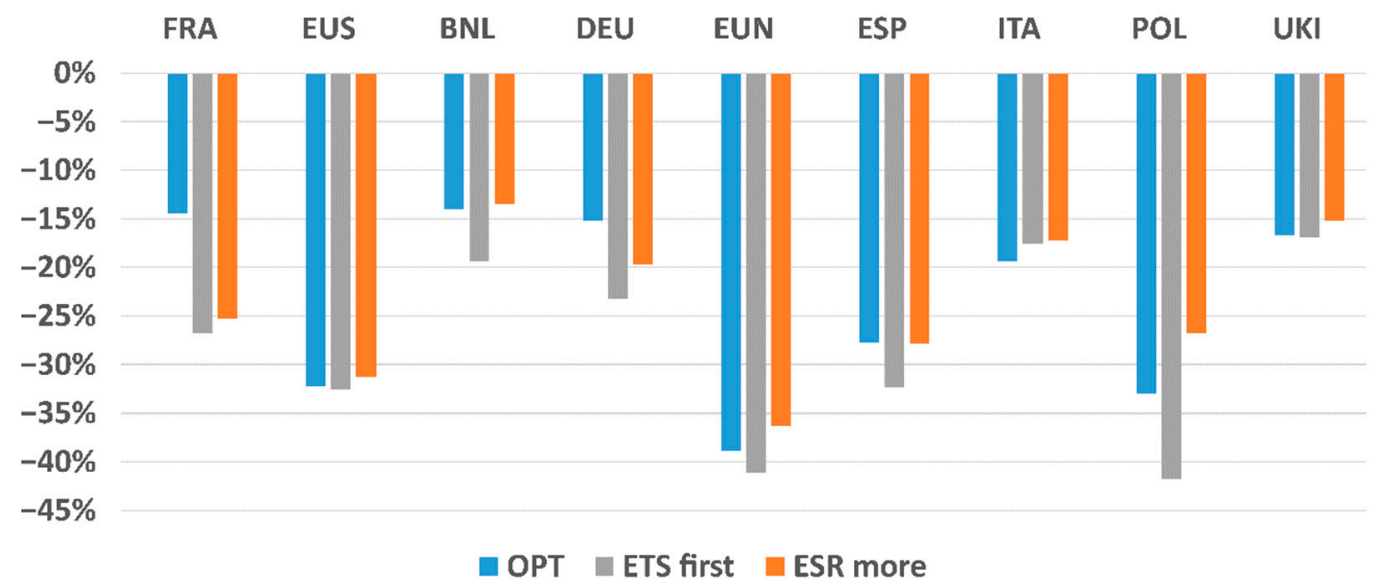

Figure 7. Reduction of $\mathrm{CO}_{2}$ in 2030 compared to the reference scenario.

Looking at the additionally required reductions in the Optimal scenario compared to the reference scenario, it is apparent that in particular, economically weaker regions such as Poland, Spain, and Portugal, south-eastern EU as well as the rather strong northern EU (which also includes the Baltic countries) had to reduce more in relation to the reference scenario, which is in line with the findings from the comparison between the Optimal 
and current targets in Figure 6. The economically weaker regions reduced their emissions in the Optimal scenario by $-27 \%$ up to $-33 \%$, compared to the previous targets of the reference scenario, which means that they had to contribute significantly larger reductions than regions such as Germany $(-15 \%)$, the Benelux countries $(-14 \%)$, France $(-14 \%)$, or the United Kingdom (-17\%).

By taking the annualised system costs (system costs include all fixed, variable, or investment costs of the technologies as well as the costs for import and distribution of energy carriers) (Figure 8) as a measure for the burden placed on the countries by the reductions in the three scenarios, we can see the reason for these unequally distributed burdens. Economically stronger countries such as Germany or France coped much better with the additional reductions than, for example, Poland, south-eastern EU, or northern EU.

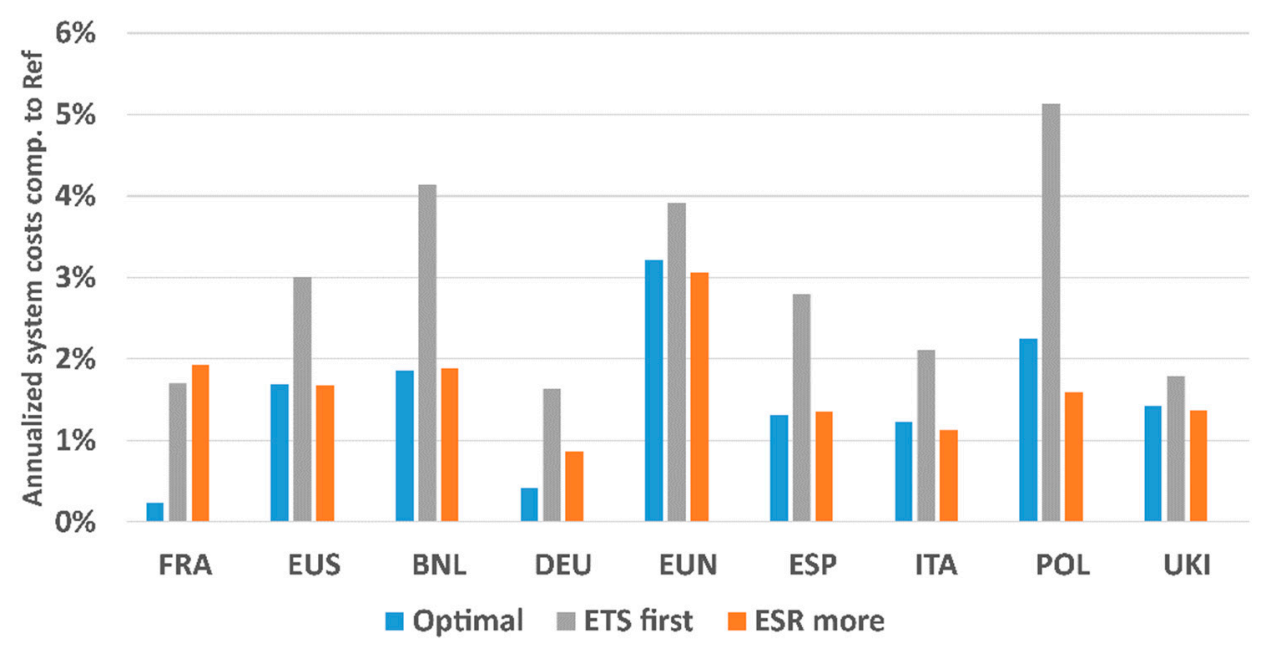

Figure 8. Deviation of the annualised system costs in 2030 compared to the reference scenario.

In the Optimal scenario, it is these regions (and Benelux) that had to relatively shoulder the largest increases in system costs. From a system perspective, these regions should mitigate more in order to achieve the set climate targets, but from a political perspective, it is also clear that these regions should be supported in this endeavour. If the system targets are to be achieved, there must either be European compensation mechanisms so that all countries are able to make their reductions, or (as in the ESR more), an uneven distribution of the reduction burden is imposed for the Non-ETS sector in order to relieve the weaker countries of some of their system costs. In this case, however, it may be accepted that the cost-optimal path is not followed.

However, this also shows the limits of energy system analysis with regard to the evaluation of political decision-making processes. With the help of TIMES PanEU, it is possible to very precisely analyse which sectors and regions have to bear which reduction burden from a system perspective in order to achieve the overarching reduction target.

TIMES PanEU can only partially analyse the interaction of the economic system with changes in the energy system; impacts on the economic structure from the demand effects are not taken into account. This is where the market-economic analysis with NEWAGE comes into play. NEWAGE has a less detailed depiction of the energy system but includes the economy as a whole in the analysis and can depict feedback effects between economic sectors. The analysis of the 2030 burden sharing within the EU is therefore continued in Section 4.3.

The conclusions of this section can thus be summarised as follows:

- For the $-55 \%$ target in 2030 , all countries must contribute significantly more in the ESR sector than agreed under the ESR targets. The economically weaker regions needed to additionally reduce their emissions in the Optimal scenario by $-27 \%$ up to $-33 \%$ compared to the current targets, which means that they had to contribute 
significantly larger relative reductions than regions such as Germany $(-15 \%)$, the Benelux countries $(-14 \%)$, France $(-14 \%)$, or the United Kingdom $(-17 \%)$.

- However, this leads to disproportionately high increases in the system costs of these countries, respectively, regions. If the system targets are to be met, there must either be European compensation mechanisms so that all countries are able to achieve their reductions. Alternatively, an uneven distribution of the reduction burdens can be prescribed for the Non-ETS sector in order to relieve the weaker countries of some of their system costs.

\subsection{Burden Sharing between the Regions in 2030 from a Macroeconomic Point of View}

To complement the analyses carried out with TIMES PanEU by adding an independent macroeconomic perspective, the same scenarios were calculated for 2030. In the following, effects are discussed in comparison to the reference scenario. Therefore, the mentioned effects occur on top of existing effects originating from the already adopted ETS and ESR targets.

From an EU-wide perspective, all of the three scenarios led to comparable losses in gross domestic product (GDP) in 2030 relative to the reference scenario. The Optimal scenario harmed EU-wide GDP development least $(-1.20 \%)$. However, the losses in ETS first $(-1.41 \%)$ exceed those of ESR more $(-1.26 \%)$ in 2030.

Gross value added (GVA) of the Non-ETS sector showed the highest losses in ETS first and the lowest in ESR more. GVA of the ETS sector was increased and almost on the same level for all of the three scenarios. The main driver behind this positive ETS sector development was electricity production.

EU prices of almost all goods from ETS sectors increased in the three scenarios relative to the reference scenario, with the strongest rise in ETS first. In contrast, EU prices of almost all goods from the Non-ETS sector decreased. ETS industries could successfully impose higher prices, but other industries further down the value chain could not do this and had to carry the burden.

Among the rising prices from the ETS sector in ETS first, electricity prices stand out with very strong increases between $22 \%$ and $107 \%$. For all EU regions, electricity prices clearly rose the most in ETS first and the least in ESR more.

Among the Green Deal scenarios, fossil fuel consumption was highest in ETS first and lowest in ESR more. The opposite was true for electricity consumption: it was highest for ESR more and lowest for ETS first. This points to the influence of electricity prices on electrification. If strong mitigation targets are not accompanied by moderate electricity prices, electrification could be impeded.

The regionally disaggregated GDP (Figure 9) view revealed losses between $-0.79 \%$ and $-1.95 \%$.

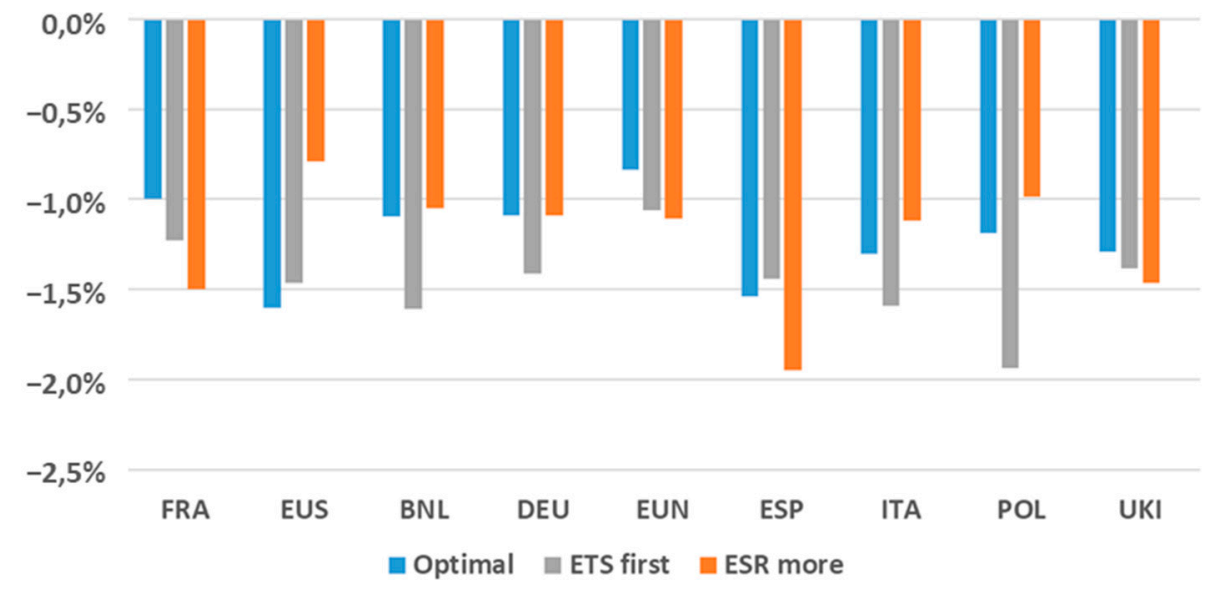

Figure 9. Deviation of EU regional GDP in 2030 compared to the reference scenario. 
In the Optimal scenario, south-eastern EU faced the strongest relative GDP loss $(-1.60 \%)$ compared to the other EU regions. Northern EU was affected the least $(-0.84 \%)$. For no region except the south-eastern EU, Optimal was the worst scenario among the three, but was the best one for the northern EU, France, and UKI.

The Optimal scenario led to more levelled absolute $\mathrm{CO}_{2}$ prices among the regions than the ETS first and ESR more scenarios. $\mathrm{CO}_{2}$ abatement relative to the reference scenario was comparably high for the south-eastern EU in all three scenarios. However, compared with the other regions, absolute weighted $\mathrm{CO}_{2}$ prices in ETS first and ESR were still rather low for the south-eastern EU (see Appendix C). Absolute Non-ETS prices were lowest among EU regions for the south-eastern EU in ETS first and ESR more. The south-eastern EU was "treated with care" in ETS first and ESR more by low Non-ETS prices, but not to the same extent in the Optimal scenario.

Northern EU reached comparably moderate relative abatement under the Optimal scenario prices. The more levelled $\mathrm{CO}_{2}$ prices helped northern EU. In the Optimal scenario, absolute weighted and Non-ETS $\mathrm{CO}_{2}$ prices did not exceed those of most other regions as much as in ETS first and in ESR more. Export from northern EU remained strong in the Optimal scenario, and losses of export value relative to the reference scenario were second lowest among the EU regions in this scenario.

Macroeconomic impacts in the ETS first scenario were most harmful for Poland $(-1.94 \%)$ and least for the northern EU $(-1.06 \%)$ relative to the reference scenario. From a macroeconomic perspective, it was the worst among the three scenarios for Poland, Benelux, Italy, and Germany, and the best one only for Spain and Portugal.

Poland was the EU region with the highest relative abatement among EU regions in ETS first. ETS abatement translates to high national abatement for Poland as it is the region with the highest GVA share of ETS sectors. However, the ETS sector even experienced above EU27 + UK average relative GVA increase. Poland faced particularly strong relative GVA losses in Non-ETS sub-sectors such as the buildings and the service sector. Relative Non-ETS GVA losses were higher than in all other EU regions. While Poland is the EU region with the highest input share of electricity among EU regions, electricity prices climbed the highest in Poland for all scenarios, but in ETS first, electricity prices rose the most - by $107 \%$ relative to the reference scenario in Poland. Germany was the region with the second largest electricity price rise in all three scenarios.

Northern EU's relative $\mathrm{CO}_{2}$ abatement in ETS first was not as high as Poland's, but still higher than the relative abatement of most other EU regions. The same applied for the GVA share of the ETS sector. Northern EU's ETS sector as a whole showed the best GVA development compared to the reference scenario in ETS first among the EU regions. In ESR more and Optimal, relative GVA increase in the ETS sector also exceeded that of all (ESR more) or most (Optimal) of the other regions, but not as much as in ETS first. Relative losses of the Non-ETS sector were rather strong, but not as strong as in Poland. Again, northern EU's exports were hardly concerned with northern EU's trade balance at its highest values relative to Reference.

In the ESR more scenario, the Spain and Portugal region experienced the highest relative GDP loss $(-1.95 \%)$ among the EU regions and south-eastern EU the lowest $(-0.79 \%)$. ESR more was the worst scenario from a macroeconomic view for Spain and Portugal, France, northern EU, and UK, and the best scenario for Poland, Italy, Benelux, and Germany.

The Spain and Portugal region has the second largest service sector among EU regions. In general, GVA share of Non-ETS industries in Spain and Portugal is slightly higher than in most other EU regions. At the same time, the Spain and Portugal regions provided the largest Non-ETS abatement relative to the reference scenario among EU regions in ESR more. After all, overall GVA of the Non-ETS sector faced the highest relative losses in Spain and Portugal compared to the EU regions in ESR more. For Spain and Portugal, France, northern EU, UKI, and Italy, service sector GVA declined most in ESR more.

South-eastern EU was least affected among EU regions in ESR more despite facing the highest relative overall and ETS-abatement compared to the other EU regions. Weighted 
and Non-ETS $\mathrm{CO}_{2}$ prices showed the strongest relative rise among EU regions. However, absolute weighted $\mathrm{CO}_{2}$ prices for south-eastern EU were still rather low, absolute Non-ETS $\mathrm{CO}_{2}$ prices were even the lowest among EU regions. In the end, the ETS sector in southeastern EU increased its GVA more than EU27 + UK average percentage-wise, and the Non-ETS sector experienced better relative GVA development than that of all other EU regions in ESR more.

The conclusions of this section can thus be summarised as follows:

- A strong reduction requirement on the ETS side can lead to an increase in electricity prices that could impede electrification;

- On the EU level, strong abatement requirement on the ETS side not only affects the energy-intensive ETS industries themselves. Depending on how well they are able to pass through increased costs, high abatement in the ETS sector can even harm the Non-ETS sector in particular;

- Economically weaker regions of the EU tend to have a greater additional economic burden in the Optimal and ETS first scenario than the others (see Table 2 below). Compensation mechanisms should be created to offset these burdens if the focus of additional abatement is not on the ESR side; and

- In the short-term (2030 perspective), a focus on increased ESR reduction instead of ETS reduction might be economically more favourable from an EU-wide perspective. From the perspective of the single EU regions, this cannot be said in all cases. For economically weak regions, economic losses tend to be limited in the short-term if stronger Non-ETS reduction with continued differentiated effort sharing is applied.

Table 2. 2030 GDP effects relative to the reference scenario. EU regions grouped according to NEWAGE base year GDP per capita.

\begin{tabular}{ccccc}
\hline GDP Per Capita & Included Regions & Optimal & ETS First & ESR More \\
\hline Low & Poland, South-Eastern EU, Spain & $-1.51 \%$ & $-1.53 \%$ & $-1.30 \%$ \\
and Portugal & $-1.18 \%$ & $-1.38 \%$ & $-1.39 \%$ \\
High & Italy, United Kingdom, France & $-1.03 \%$ & $-1.36 \%$ & $-1.08 \%$ \\
\hline
\end{tabular}

\section{Burden Sharing in $\mathbf{2 0 5 0}$}

Although the focus of this paper was on the implications of the tightened targets of the Green Deal in 2030, we consider it imperative to also examine the long-term effects of the tightened targets (i.e., climate neutrality in 2050). For these considerations, only TIMES PanEU will be used in the following.

We begin with the total GHG emissions for the individual countries shown in Figure 10, which arise under the three different scenarios:

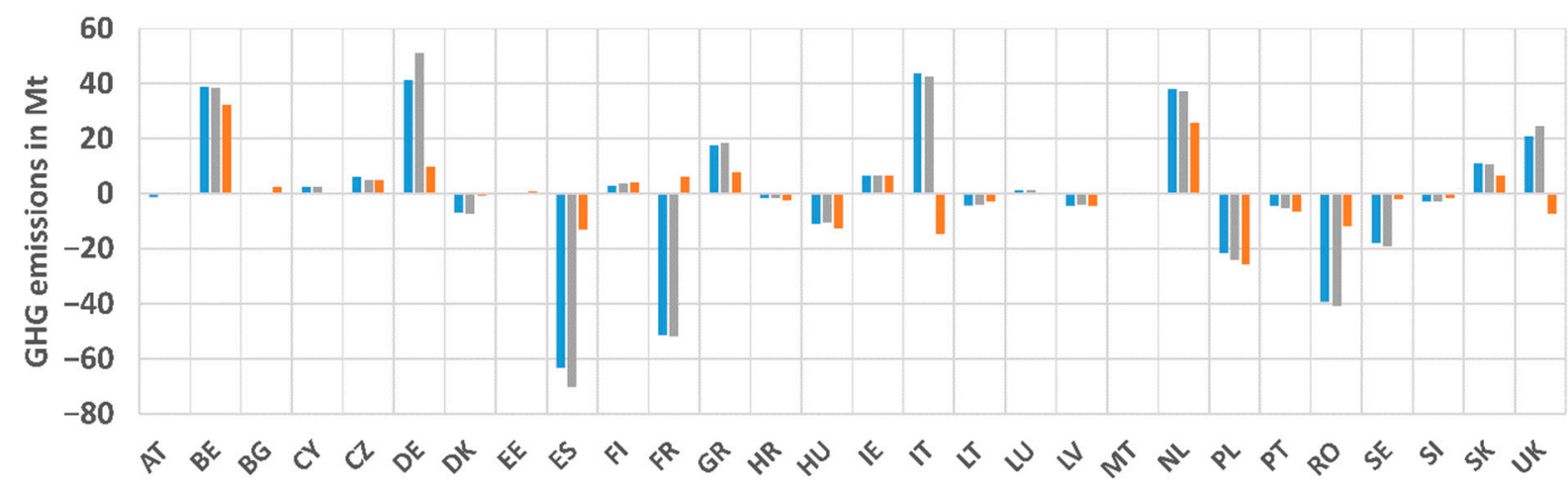

Figure 10. Total greenhouse gas emissions by country in 2050. 
It can be observed that, from a cost-optimal system perspective, some of the countries had to bring their total GHG emissions into negative range by utilising electricity from biomass plus CCS in order to compensate for the remaining residual emissions of other countries, with Spain accounting for the largest total negative emissions of up to $-65 \mathrm{Mt}$ per year, depending on the scenario.

It should be noted that negative emissions from BECCS were used in all scenarios for the reasons mentioned in Section 3.1. For this reason, Optimal and ETS first barely differed in 2050, as in both scenarios, more than $100 \%$ mitigation took place in the ETS sector. It is noticeable that fewer negative emissions were needed in ESR more. This is mainly due to mitigation in the agricultural sector, where technological mitigation options are extremely costly. However, when they were necessary due to national requirements and the general ESR reduction of $95 \%$, this also reduced the required BECCS use to compensate for agricultural emissions compared to the Optimal scenario.

The countries that dropped into the negative emissions range were, due to the use of BECCS, countries with high potential to grow biomass on arable land [36]: France, Spain, Romania, and Poland as well as partly Sweden or Hungary. In these countries, there was therefore automatically BECCS potential due to their biomass potential. It can also be seen here that it is predominantly these countries that benefited from ESR more, as it was no longer necessary to compensate for the residual emissions of other countries (except for Poland, which suffered from the $80 \%$ reduction in the ESR sector).

In accordance with the analysis in Section 4.2, we wanted to use not only the emissions, but also the impacts of the reductions in the system costs to evaluate the burden-sharing between the regions; these are shown for this reason in Figure 11.

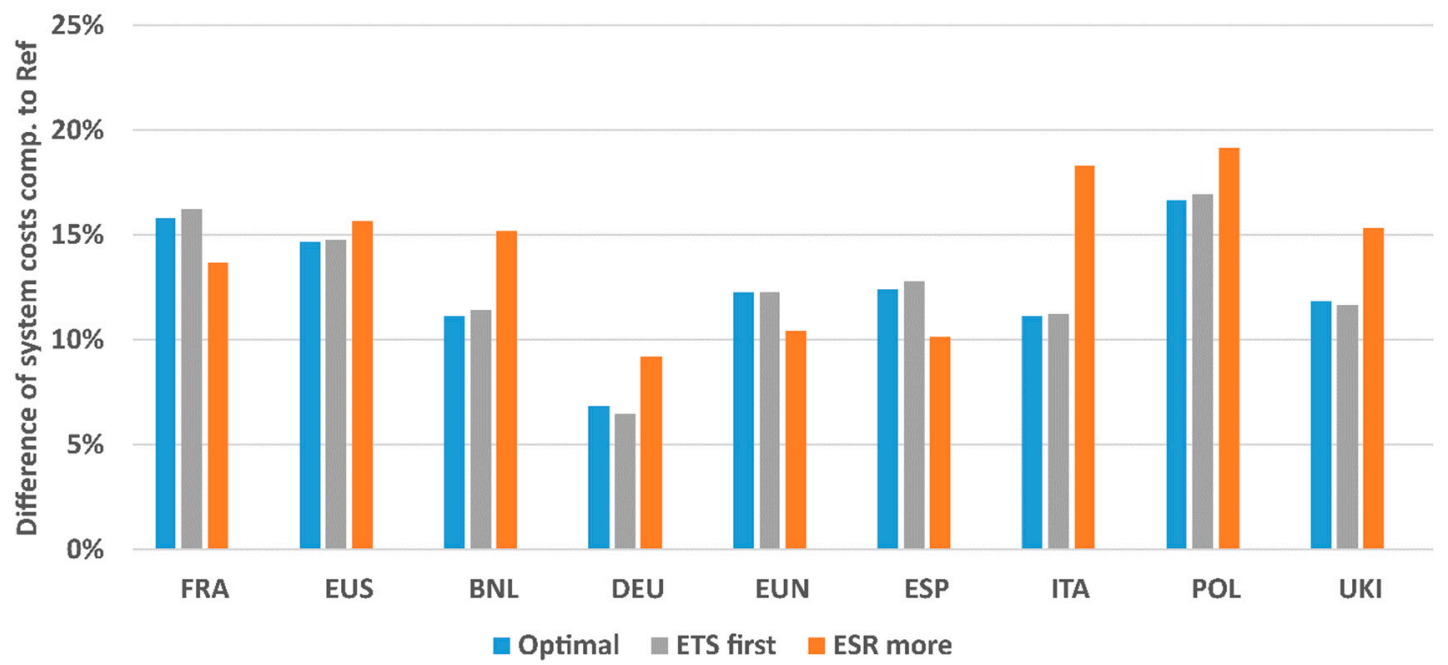

Figure 11. Deviation of the annualised system costs in 2050 compared to the reference scenario.

Due to the negative emissions, ETS first and Optimal hardly differed in system costs. There were only slight differences between the regions. In the case of the ESR more, however, there were very distinct differences in 2050. Due to the condition that all countries had to reduce at least $80 \%$ in the ESR sector, some regions were burdened significantly more than in the Optimal case. Italy, south-eastern EU, the Benelux countries, and Poland are particularly worth mentioning here.

Countries such as Bulgaria, Cyprus, Lithuania, Latvia, Malta, or Slovakia had to reduce significantly further in the strict regime of the ESR more than would have been optimal from a system perspective. The main reason for these different emission levels is the role of agriculture, which represents the most expensive reduction options in the system. A lot of technical effort has to be made here, which costs money. If livestock farming accounts for a relatively larger share of emissions, it becomes tremendously expensive for these countries to further mitigate these emissions. Therefore, these emissions were often 
not reduced to the maximum possible in the Optimal, but instead, were compensated by negative emissions.

However, due to the stipulation of a 95\% reduction in the entire ESR regime, all countries were forced to make greater reductions, which is also reflected in $1.5 \%$ higher EU-wide system costs in ESR more compared to the Optimal scenario. Only countries with high negative emissions in the other scenarios benefited from this. Since these costs were not credited in any form according to the current status, but only burdened their own energy system, they benefited from a scenario in which residual emissions from the ESR were low (e.g., France, Spain, Romania).

The contrast to the Energy System in 2030 becomes obvious: while weaker countries should achieve more in the ESR in the medium-term from a system perspective, they should not be required to reduce too much here in the long-term. Especially in countries where agriculture accounts for a large share of the energy system and emissions, such targets would only be achievable with great effort and at high cost. In this case, the burden distribution between countries would be disadvantageous.

From a system perspective, the use of BECCS is unavoidable and makes sense in many countries. From an economic, political, and financial point of view, however, it is not yet reasonable for these countries. In order to realise the negative emissions necessary from a system perspective, regulatory or financial incentives must be established. It is conceivable, for instance, that the ETS could provide a payment for negative emissions that would make the use of the technology profitable. Regardless of the concrete design of these incentives, the generation of negative emissions must become economically attractive, otherwise the achievement of complete climate neutrality is unrealistic.

The conclusions of this section can thus be summarised as follows:

- A strict reduction regime that imposes strong mitigation targets on all countries is not optimal from a system perspective, which is reflected in 1.5\% higher EU-wide system costs; in particular, countries with large shares of agricultural emissions should not be given overly ambitious targets; and

- To compensate for these residual emissions, countries with high biomass potentials should produce negative emissions. Countries that provide these additional mitigation burdens beyond climate neutrality must be financially compensated.

\section{Discussion}

In order to better correlate the TIMES and NEWAGE findings, central results of the models were compared and interpreted in the following.

In Section 4.3, NEWAGE determined a higher electricity price for the ETS first scenario, which may indicate a hindrance for electrification. TIMES identified an identical problem, since the transport sector is electrified to a much lesser extent in this scenario; in ETS first, electricity accounts for only $11 \%$ of the final energy consumption compared to $15 \%$ in the Optimal scenario (see Figure 5b). However, this effect was not observable in other sectors, as described in Section 4.1. Although higher electricity prices also resulted in TIMES, the prices for district heating, for example, rose much more sharply in the building sector, which is why the higher electricity price is not reflected here.

The GDP losses arising from burden sharing within the EU as calculated by NEWAGE (see Section 4.3) showed a slightly higher burden on the EU as a whole for ETS first than for the Optimal scenario for 2030 ( $-1.41 \%$ compared to $-1.20 \%)$. Although TIMES PanEU in Section 4.2. saw a larger discrepancy in total system costs between these two scenarios of $+2.6 \%$ for ETS first compared to $+1.3 \%$ in the Optimal scenario or $+1.5 \%$ in ESR more, the direction was the same. A too strong focus on mitigation in the ETS sector is not cost-optimal from both a macroeconomic and an energy system perspective to achieve the goals of the Green Deal.

We considered negative emissions due to agriculture to be indispensable, but there are certainly studies that have arrived at other results. The absolute level is, of course, directly dependent on the assumption of a decline in livestock farming. Should the 50\% 
prove to be unrealistic, the necessary compensation through negative emissions would be significantly higher, as the absolute values of negative emissions, distributed over the countries, is dependent on our assumed potentials for biomass.

As economically weak EU regions were impacted most negatively in the Optimal scenario from an energy system cost and macroeconomic perspective, a central finding of our work is the necessity of compensation mechanisms. Further research should be conducted in this field, especially with regard to the concrete design of these measures. An expansion of the Just Transition Fund would be conceivable, but more in-depth studies should be conducted on this.

Furthermore, we considered coal phaseouts as national climate measures in the context of this article. We are aware that there are a large number of national climate targets that are planned or have already been implemented. We have decided not to include these measures in order to limit the horizon of the study, but these national programmes should be examined in terms of their interactions with the Green Deal.

\section{Conclusions}

- A too heavy focus on reductions in the ETS sector in 2030 leads to two negative effects. First, district heating, which optimally contributes to decarbonisation, is deployed less in the building sector ( $8 \%$ of final energy consumption in ETS first compared to $12 \%$ in the Optimal scenario). Second, tightened targets for the power sector lead to higher electricity prices, meaning that electric options are less deployed in the transport sector, which results in higher emissions in that sector. Reductions should be made in a way between the ESR and ETS sectors so that an emissions budget ratio of 61 to 39 results, similar to what the EU Commission proposes.

- From an energy system perspective, economically weaker countries should reduce their emissions significantly more by 2030 than previously envisaged in the ESR targets in order to achieve the EU-wide $-55 \%$ targets at optimal cost. The economically weaker regions need to additionally reduce their emissions in the Optimal scenario by up to $-33 \%$ compared to the current targets.

- However, the macroeconomic studies show the high economic burdens that result from distributing emission budgets according to a gross EU27 + UK optimum, which makes support via compensation measures absolutely necessary. Depending on the policy scenario applied, GDP losses in the range of $-0.79 \%$ and $-1.95 \%$ relative to baseline are found for single EU regions.

- An equally strict mitigation regime for all countries in 2050 is not optimal from a system perspective, which is reflected in 1.5\% higher EU-wide system costs. In particular, countries with large shares of agricultural emissions should not be given excessively strong targets.

- In contrast, countries with high biomass potentials should generate negative emissions to compensate for these residual emissions. Countries that shoulder these additional mitigation burdens beyond climate neutrality must be financially compensated.

Author Contributions: Conceptualization, F.K., R.C.M., V.S., M.B. and U.F.; Formal analysis, F.K. and J.S.; Investigation, F.K. and J.S.; Methodology, F.K. and J.S.; Project administration, M.B. and U.F.; Software, F.K. and J.S.; Supervision, M.B.; Validation, F.K., J.S., R.C.M., V.S., M.B. and U.F.; Visualization, F.K. and J.S.; Writing—original draft, F.K. and J.S.; Writing—review \& editing, F.K., J.S., M.B. and U.F. All authors have read and agreed to the published version of the manuscript.

Funding: This research was funded by the German Federal Ministry of Education and Research in the ARIADNE Project, grant number 03SFK5H0.

Institutional Review Board Statement: Not applicable.

Informed Consent Statement: Not applicable.

Data Availability Statement: The data presented in this study are available on request from the corresponding author. 
Acknowledgments: The authors gratefully acknowledge the support of the Open Access Publication Fund of the University of Stuttgart.

Conflicts of Interest: The authors declare no conflict of interest.

Appendix A. Scenario Framework by Country

Table A1. GHG emission targets in the ESR sector for the EU27 + UK countries (extension of Table 1).

\begin{tabular}{|c|c|c|c|c|c|}
\hline & \multirow{2}{*}{$\begin{array}{c}2005 \\
\text { Statistics } \\
{[43]}\end{array}$} & \multicolumn{2}{|c|}{2030} & \multicolumn{2}{|c|}{2050} \\
\hline & & $\begin{array}{l}\text { OPT \& ETS } \\
\text { First [2] }\end{array}$ & $\begin{array}{c}\text { ESR More } \\
\text { [10] }\end{array}$ & $\begin{array}{c}\text { OPT \& ETS } \\
\text { First }\end{array}$ & $\begin{array}{c}\text { ESR More } \\
\text { [10] }\end{array}$ \\
\hline Austria & $53.51 \mathrm{Mt}$ & $-36 \%$ & $-51 \%$ & $-36 \%$ & \\
\hline Belgium & $76.59 \mathrm{Mt}$ & $-35 \%$ & $-51 \%$ & $-35 \%$ & \\
\hline Bulgaria & $20.79 \mathrm{Mt}$ & $\pm 0 \%$ & $-25 \%$ & $\pm 0 \%$ & \\
\hline Cyprus & $3.8 \mathrm{Mt}$ & $-24 \%$ & $-45 \%$ & $-24 \%$ & \\
\hline Czech Rep. & $57.48 \mathrm{Mt}$ & $-14 \%$ & $-39 \%$ & $-14 \%$ & \\
\hline Germany & $454.74 \mathrm{Mt}$ & $-38 \%$ & $-51 \%$ & $-38 \%$ & \\
\hline Denmark & $39.6 \mathrm{Mt}$ & $-39 \%$ & $-53 \%$ & $-39 \%$ & \\
\hline Estonia & $5.62 \mathrm{Mt}$ & $-13 \%$ & $-36 \%$ & $-13 \%$ & \\
\hline Spain & $225.89 \mathrm{Mt}$ & $-26 \%$ & $-48 \%$ & $-26 \%$ & \\
\hline Finland & $31.09 \mathrm{Mt}$ & $-39 \%$ & $-51 \%$ & $-39 \%$ & \\
\hline France & $378.2 \mathrm{Mt}$ & $-37 \%$ & $-51 \%$ & $-37 \%$ & \\
\hline Greece & $57.48 \mathrm{Mt}$ & $-16 \%$ & $-39 \%$ & $-16 \%$ & \\
\hline Hungary & $41.63 \mathrm{Mt}$ & $-7 \%$ & $-31 \%$ & $-7 \%$ & \\
\hline Ireland & $45.55 \mathrm{Mt}$ & $-30 \%$ & $-55 \%$ & $-30 \%$ & \\
\hline Croatia & $15.94 \mathrm{Mt}$ & $-7 \%$ & $-31 \%$ & $-7 \%$ & $-80 \%$ \\
\hline Italy & $314.26 \mathrm{Mt}$ & $-33 \%$ & $-50 \%$ & $-33 \%$ & \\
\hline Lithuania & $9.78 \mathrm{Mt}$ & $-9 \%$ & $-33 \%$ & $-9 \%$ & \\
\hline Luxembourg & $9.98 \mathrm{Mt}$ & $-40 \%$ & $-51 \%$ & $-40 \%$ & \\
\hline Latvia & $7.9 \mathrm{Mt}$ & $-6 \%$ & $-31 \%$ & $-6 \%$ & \\
\hline Malta & $0.82 \mathrm{Mt}$ & $-19 \%$ & $-43 \%$ & $-19 \%$ & \\
\hline Netherlands & $116.26 \mathrm{Mt}$ & $-36 \%$ & $-52 \%$ & $-36 \%$ & \\
\hline Poland & $166 \mathrm{Mt}$ & $-7 \%$ & $-31 \%$ & $-7 \%$ & \\
\hline Portugal & $40.27 \mathrm{Mt}$ & $-17 \%$ & $-39 \%$ & $-17 \%$ & \\
\hline Romania & $73.71 \mathrm{Mt}$ & $-2 \%$ & $-28 \%$ & $-2 \%$ & \\
\hline Sweden & $39.79 \mathrm{Mt}$ & $-40 \%$ & $-52 \%$ & $-40 \%$ & \\
\hline Slovenia & $10.96 \mathrm{Mt}$ & $-15 \%$ & $-41 \%$ & $-15 \%$ & \\
\hline Slovakia & $20.77 \mathrm{Mt}$ & $-12 \%$ & $-36 \%$ & $-12 \%$ & \\
\hline UK & $368.14 \mathrm{Mt}$ & $-37 \%$ & $-50 \%$ & $-37 \%$ & \\
\hline
\end{tabular}


Appendix B. NEWAGE Structure

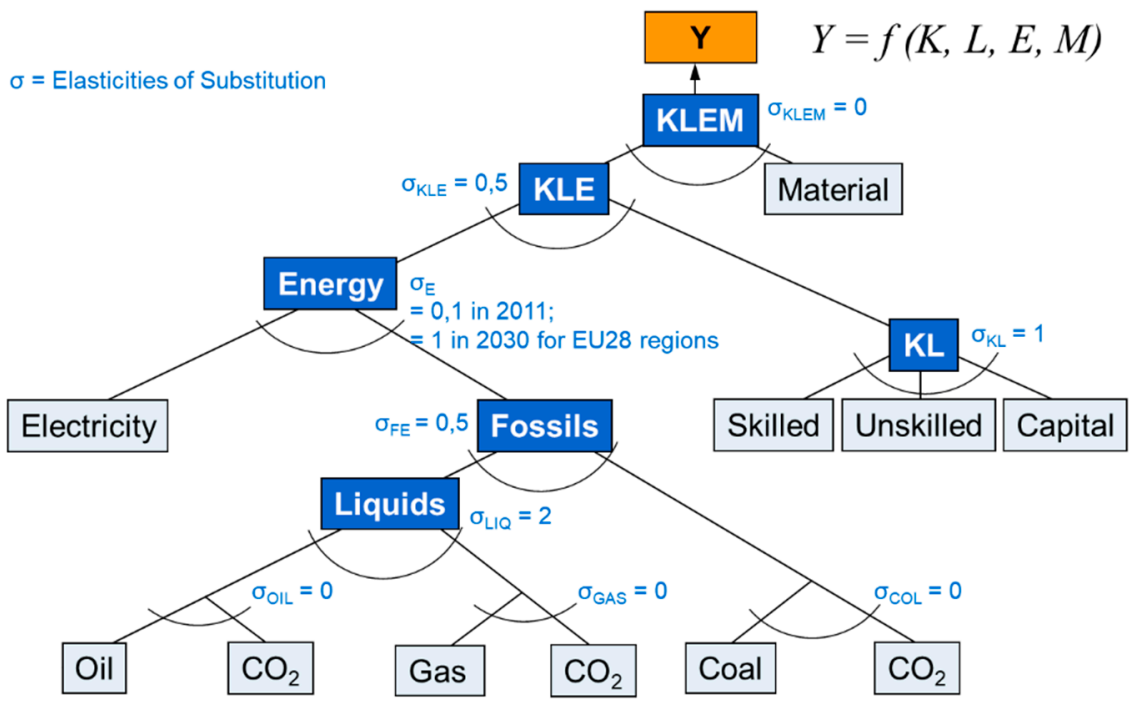

Figure A1. Nesting of NEWAGE CES production functions (given values for elasticities of substitution apply for 19 out of the 23 production sectors).

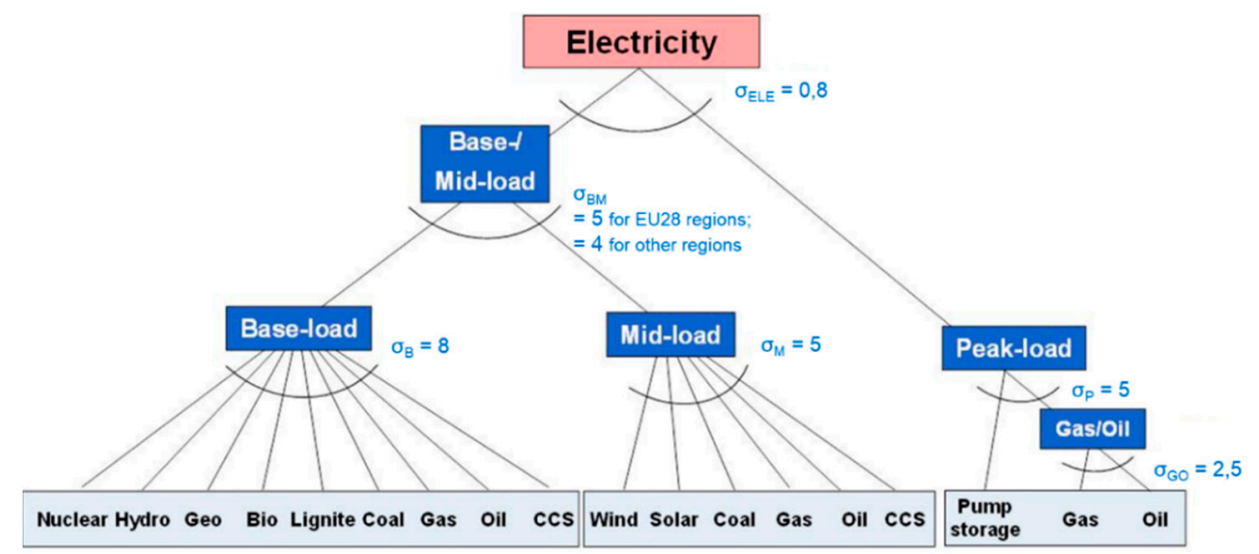

Figure A2. NEWAGE disaggregation of electricity generation.

\section{Appendix C. Extended NEWAGE Scenario Results}

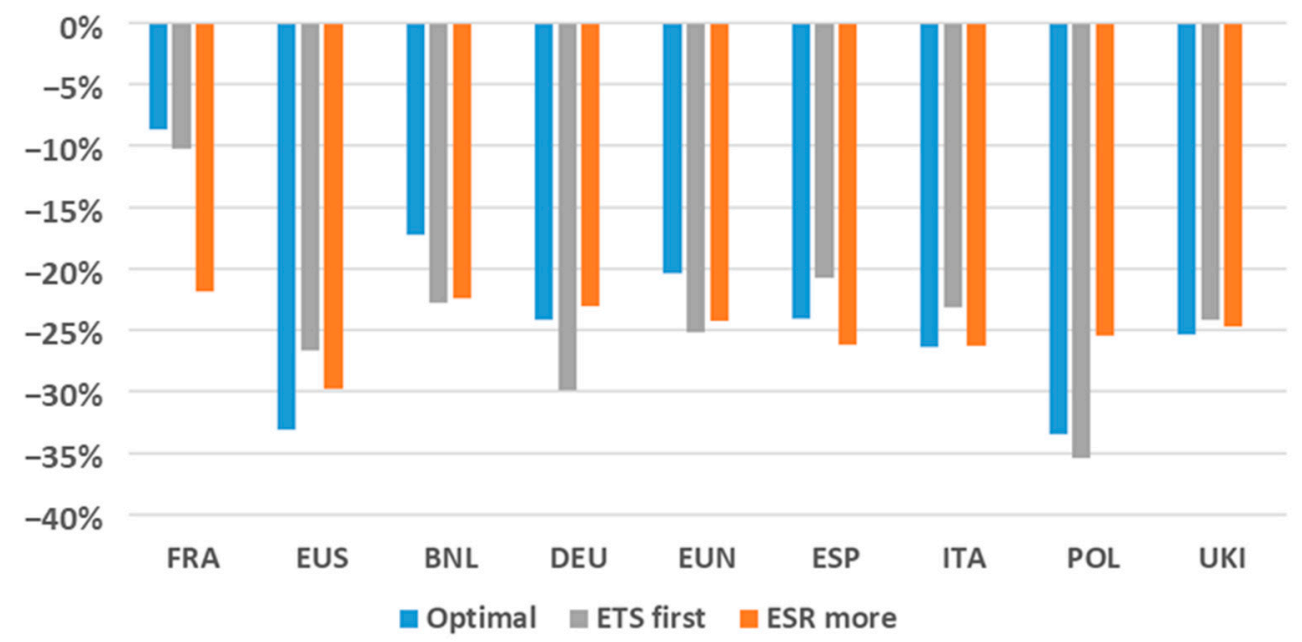

Figure A3. Deviation of EU27 + UK regional $\mathrm{CO}_{2}$ emissions in 2030 relative to the reference scenario. 


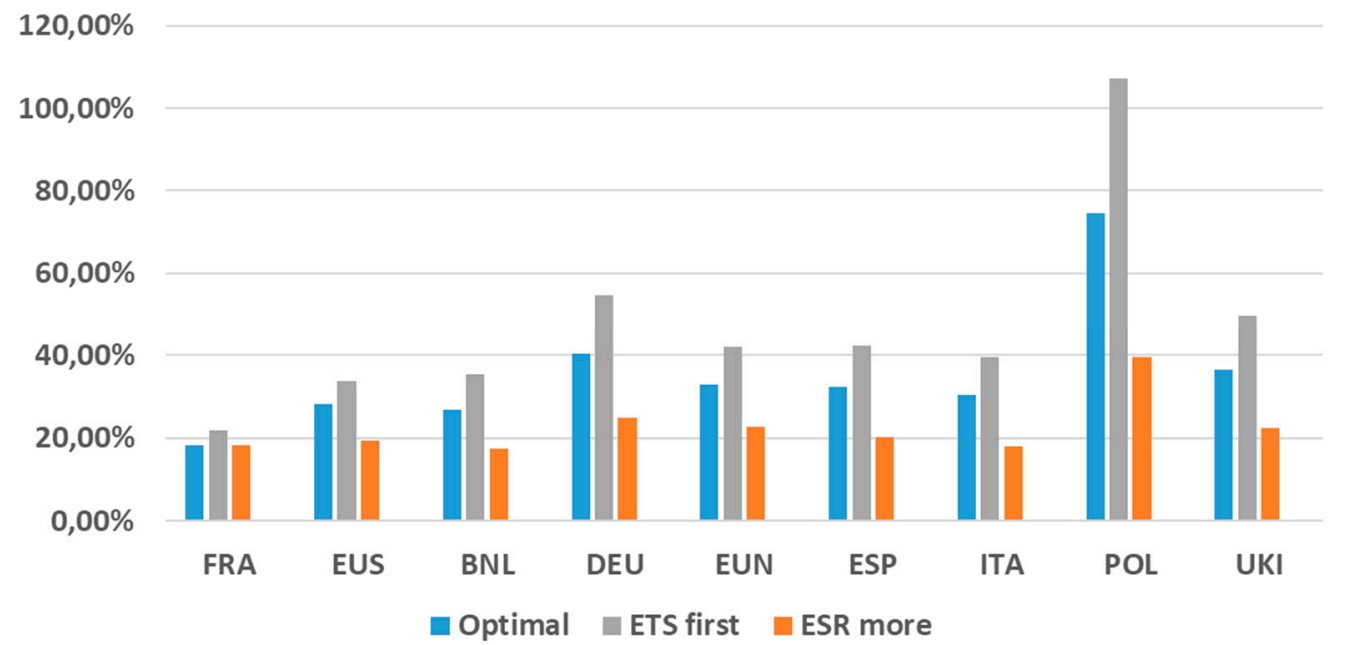

Figure A4. Deviation of EU27 + UK regional electricity prices in 2030 relative to the reference scenario.

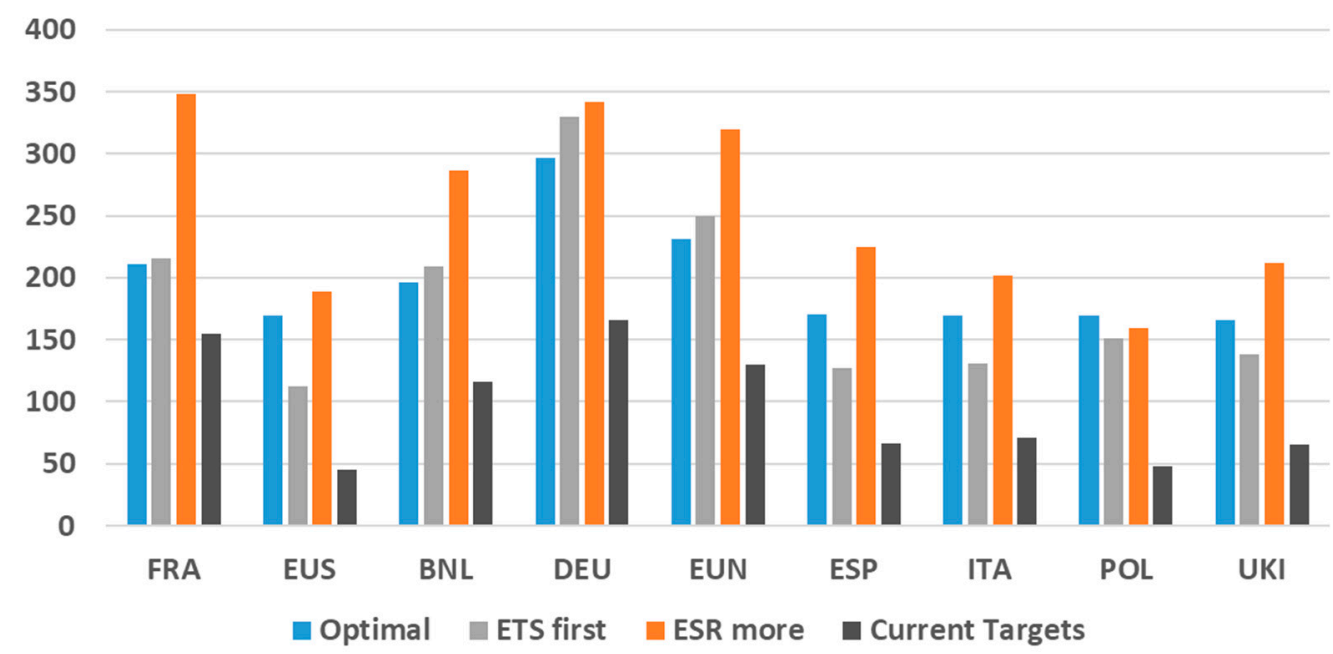

Figure A5. EU27 + UK regional absolute weighted $\mathrm{CO}_{2}$ prices in 2030 [€2020].

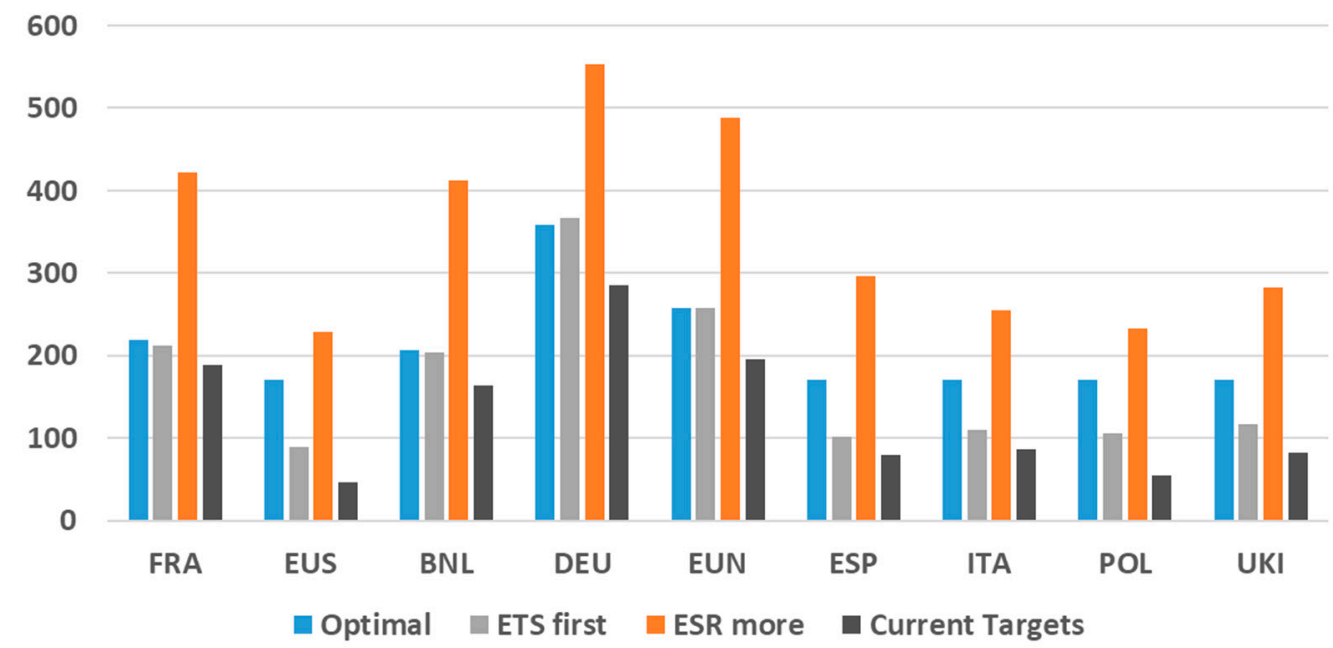

Figure A6. EU27 + UK regional absolute Non-ETS $\mathrm{CO}_{2}$ prices in 2030 [€2020]. 


\section{References}

1. European Comission. Communication from the Comission to the European Parliament, the European Council, the Council, the European Economic and Social Committee and the Committee of the Regions; The European Green Deal: Brussels, Belgium, 2019.

2. European Comission Effort Sharing 2021-2030: Targets and Flexibilities. Available online: https://ec.europa.eu/clima/euaction/effort-sharing-member-states-emission-targets/effort-sharing-2021-2030-targets-and_en (accessed on 29 October 2021).

3. Simoes, S.; Nijs, W.; Ruiz, P.; Sgobbi, A.; Thiel, C. Comparing Policy Routes for Low-Carbon Power Technology Deployment in EU-An Energy System Analysis. Energy Policy 2017, 101, 353-365. [CrossRef]

4. Knopf, B.; Chen, Y.-H.H.; De Cian, E.; Förster, H.; Kanudia, A.; Karkatsouli, I.; Keppo, I.; Koljonen, T.; Schumacher, K.; Van Vuuren, D.P. Beyond 2020-Strategies and Costs for Transforming the European Energy System. Clim. Chang. Econ. 2013, 04, 1340001. [CrossRef]

5. Gils, H.C.; Scholz, Y.; Pregger, T.; Luca de Tena, D.; Heide, D. Integrated Modelling of Variable Renewable Energy-Based Power Supply in Europe. Energy 2017, 123, 173-188. [CrossRef]

6. $\quad$ Ringkjøb, H.-K.; Haugan, P.M.; Seljom, P.; Lind, A.; Wagner, F.; Mesfun, S. Short-Term Solar and Wind Variability in Long-Term Energy System Models-A European Case Study. Energy 2020, 209, 118377. [CrossRef]

7. Oei, P.-Y.; Burandt, T.; Hainsch, K.; Löffler, K.; Kemfert, C. Lessons from Modeling 100\% Renewable Scenarios Using GENeSYSMOD. EEEP 2020, 9, 103-120. [CrossRef]

8. Connolly, D.; Lund, H.; Mathiesen, B.V.; Leahy, M. A Review of Computer Tools for Analysing the Integration of Renewable Energy into Various Energy Systems. Appl. Energy 2010, 87, 1059-1082. [CrossRef]

9. Jäger-Waldau, A.; Kougias, I.; Taylor, N.; Thiel, C. How Photovoltaics Can Contribute to GHG Emission Reductions of 55\% in the EU by 2030. Renew. Sustain. Energy Rev. 2020, 126, 109836. [CrossRef]

10. Graichen, J.; Matthes, F.; Gores, S.; Fallasch, F. How to Raise Europe's Climate Ambitions for 2030: Implementing a -55\% Target in EU Policy Architecture; Agora Energiewende: Berlin, Germany, 2020.

11. Pietzcker, R.C.; Osorio, S.; Rodrigues, R. Tightening EU ETS Targets in Line with the European Green Deal: Impacts on the Decarbonization of the EU Power Sector. Appl. Energy 2021, 293, 29. [CrossRef]

12. Luderer, G.; Vrontisi, Z.; Bertram, C.; Edelenbosch, O.Y.; Pietzcker, R.C.; Rogelj, J.; De Boer, H.S.; Drouet, L.; Emmerling, J.; Fricko, O.; et al. Residual Fossil $\mathrm{CO}_{2}$ Emissions in 1.5-2 ${ }^{\circ} \mathrm{C}$ Pathways. Nat. Clim. Chang. 2018, 8, 626-633. [CrossRef]

13. Fragkos, P. Global Energy System Transformations to $1.5^{\circ} \mathrm{C}$ : The Impact of Revised Intergovernmental Panel on Climate Change Carbon Budgets. Energy Technol. 2000, 8, 2000395. [CrossRef]

14. IPCC. Global Warming of $1.5^{\circ} \mathrm{C}$. An IPCC Special Report on the Impacts of Global Warming of $1.5^{\circ} \mathrm{C}$ above Pre-Industrial Levels and Related Global Greenhouse Gas Emission Pathways, in the Context of Strengthening the Global Response to the Threat of Climate Change, Sustainable Development, and Efforts to Eradicate Poverty; Intergovernmental Panel on Climate Change (IPCC): Geneva, Switzerland, 2018.

15. Hainsch, K.; Burandt, T.; Löffler, K.; Kemfert, C.; Oei, P.-Y.; von Hirschhausen, C. Emission Pathways Towards a Low-Carbon Energy System for Europe: A Model-Based Analysis of Decarbonization Scenarios. Energy J. 2021, 42. [CrossRef]

16. Victoria, M.; Zhu, K.; Brown, T.; Andresen, G.B.; Greiner, M. Early Decarbonisation of the European Energy System Pays Off. Nat. Commun. 2020, 11, 6223. [CrossRef] [PubMed]

17. Sgobbi, A.; Nijs, W.; De Miglio, R.; Chiodi, A.; Gargiulo, M.; Thiel, C. How Far Away Is Hydrogen? Its Role in the Medium and Long-Term Decarbonisation of the European Energy System. Int. J. Hydrogen Energy 2016, 41, 19-35. [CrossRef]

18. Klein, D.; Bauer, N.; Bodirsky, B.; Dietrich, J.P.; Popp, A. Bio-IGCC with CCS as a Long-Term Mitigation Option in a Coupled Energy-System and Land-Use Model. Energy Procedia 2011, 4, 2933-2940. [CrossRef]

19. Smith, P.; Davis, S.J.; Creutzig, F.; Fuss, S.; Minx, J.; Gabrielle, B.; Kato, E.; Jackson, R.B.; Cowie, A.; Kriegler, E.; et al. Biophysical and Economic Limits to Negative $\mathrm{CO}_{2}$ Emissions. Nat. Clim. Chang. 2016, 6, 42-50. [CrossRef]

20. Impact Assessment Accompanying the Document Communication from the European Commission to the European Parliament, the Council, the European Economic and Social Committee and the Committee of the Regions Stepping up Europe's 2030 Climate Ambition Investing in a Climate-Neutral Future for the Benefit of Our People (Part1/2); European Commission: Brussels, Belgium, 2020.

21. Meyer-Ohlendorf, N.; Bart, I. Climate Action Regulation 2.0-EU Framework for Making Non-ETS Sectors Climate Neutral; Ecologic Institut: Berlin, Germany, 2020; p. 25.

22. European Comission. Proposal for a Regulation of the European Parliament and of the Council Amending Regulation (EU) $2018 / 842$ on Binding Annual Greenhouse Gas Emission Reductions by Member States from 2021 to 2030 Contributing to Climate Action to Meet Commitments under the Paris Agreement; European Commission: Brusssels, Belgium, 2021.

23. EU Carbon Market Will Be Extended to Buildings and Transport, von Der Leyen Confirms. Available online: https: //www.euractiv.com/section/energy/news/eu-carbon-market-will-be-extended-to-buildings-and-transport-von-der-leyenconfirms/ (accessed on 25 November 2021).

24. Babonneau, F.; Haurie, A.; Vielle, M. Welfare Implications of EU Effort Sharing Decision and Possible Impact of a Hard Brexit. Energy Econ. 2018, 74, 470-489. [CrossRef]

25. Korkmaz, P.; Gardumi, F.; Avgerinopoulos, G.; Blesl, M.; Fahl, U. A Comparison of Three Transformation Pathways towards a Sustainable European Society-An Integrated Analysis from an Energy System Perspective. Energy Strategy Rev. 2020, $28,100461$. [CrossRef]

26. Nijs, W.; Ruiz, P. 01_JRC-EU-TIMES Full Model. European Commission, Joint Research Centre (JRC) [Dataset]. Available online: http:/ / data.europa.eu/89h/8141a398-41a8-42fa-81a4-5b825a51761b (accessed on 26 November 2021). 
27. Korkmaz, P.; Cunha Montenegro, R.; Schmid, D.; Blesl, M.; Fahl, U. On the Way to a Sustainable European Energy System: Setting Up an Integrated Assessment Toolbox with TIMES PanEU as the Key Component. Energies 2020, 13, 707. [CrossRef]

28. Remme, U. Overview of TIMES: Parameters, Primal Variables E Equations; Presented at the ETSAP Workshop: Brasilia, Brazil, 2007.

29. Loulou, R.; Lehtilä, A.; Kanudia, A.; Remme, U.; Goldstein, G. Documentation for the TIMES Model PART II; Energy Technology Systems Analysis Programme (ETSAP): Paris, France, 2016; p. 38.

30. Schmid, D.; Korkmaz, P.; Blesl, M.; Fahl, U.; Friedrich, R. Analyzing Transformation Pathways to a Sustainable European Energy System-Internalization of Health Damage Costs Caused by Air Pollution. Energy Strategy Rev. 2019, 26, 100417. [CrossRef]

31. Bicer, Y.; Dincer, I.; Vezina, G. Comprehensive Evaluation of $\mathrm{NH}_{3}$ Production and Utilization Options for Clean Energy Applications. 2017. Available online: https:/ / zeropollution2050.com/wp-content/uploads/2021/01/MITACS-Canada-AmmoniaReport.pdf (accessed on 21 November 2021).

32. Europe Beyond Coal Overview of National Phase-out Announcements March 2021. Available online: https://beyond-coal.eu/20 21/03/03/overview-of-national-phase-out-announcements-march-2021/ (accessed on 10 March 2021).

33. Ruiz, P.; Sgobbi, A.; Nijs, W.N.; Thiel, C.; Dalla Longa, F.; Kober, T.; Elbersen, B.; Hengeveld, G.; European Commission; Joint Research Centre; et al. The JRC-EU-TIMES Model: Bioenergy Potentials for EU and Neighbouring Countries; Publications Office: Luxembourg, 2015; ISBN 978-92-79-53879-7.

34. Ruiz, P.; Nijs, W.; Tarvydas, D.; Sgobbi, A.; Zucker, A.; Pilli, R.; Jonsson, R.; Camia, A.; Thiel, C.; Hoyer-Klick, C.; et al. ENSPRESOAn Open, EU-28 Wide, Transparent and Coherent Database of Wind, Solar and Biomass Energy Potentials. Energy Strategy Rev. 2019, 26, 100379. [CrossRef]

35. Gerhardt, C.; Suhlmann, G.; Ziemßen, F.; Donnan, D.; Warschun, M.; Kühnle, H.J. How Will Cultured Meat and Meat Alternatives Disrupt the Agricultural and Food Industry? Ind. Biotechnol. 2020, 16, 262-270. [CrossRef]

36. Lucas, P.L.; van Vuuren, D.P.; Olivier, J.G.J.; den Elzen, M.G.J. Long-Term Reduction Potential of $\mathrm{Non}^{-\mathrm{CO}_{2}}$ Greenhouse Gases. Environ. Sci. Policy 2007, 10, 85-103. [CrossRef]

37. IEA World Energy Outlook 2020; IEA: Paris, France, 2020.

38. Impact Assessment Accompanying the Document Communication from the European Commission to the European Parliament, the Council, the European Economic and Social Committee and the Committee of the Regions Stepping up Europe's 2030 Climate Ambition Investing in a Climate-Neutral Future for the Benefit of Our People (Part 2/2); European Commission: Brussels, Belgium, 2012.

39. Aguiar, A.; Narayanan, B.; McDougall, R. An Overview of the GTAP 9 Data Base. J. Glob. Econ. Anal. 2016, 1, 181-208. [CrossRef]

40. Stadler, K.; Wood, R.; Bulavskaya, T.; Södersten, C.-J.; Simas, M.; Schmidt, S.; Usubiaga, A.; Acosta-Fernández, J.; Kuenen, J.; Bruckner, M.; et al. EXIOBASE 3: Developing a Time Series of Detailed Environmentally Extended Multi-Regional Input-Output Tables. J. Ind. Ecol. 2018, 22, 502-515. [CrossRef]

41. Revision for Phase 4 (2021-2030). Available online: https:/ / ec.europa.eu/clima/eu-action/eu-emissions-trading-system-eu-ets/ revision-phase-4-2021-2030_en (accessed on 10 November 2021).

42. Stepping Up Europe's 2030 Climate Ambition Investing in a Climate-Neutral Future for the Benefit of Our People. Available online: https: / / eur-lex.europa.eu/legal-content/EN/TXT/?uri=CELEX\%3A52020DC0562 (accessed on 18 November 2021).

43. National Inventory Submissions 2020 I UNFCCC. Available online: https:/ / unfccc.int/ghg-inventories-annex-i-parties/2020 (accessed on 18 November 2021).

44. Abrell, J.; Rausch, S. A Smart Design of New EU Emissions Trading Could Save 61 Per Cent of Mitigation Costs. ZEW Policy Brief. 2021. Available online: https:/ / ftp.zew.de/pub/zew-docs/policybrief/en/pb05-21.pdf (accessed on 29 October 2021). 